\title{
Manganese Superoxide Dismutase Protects nNOS Neurons from NMDA and Nitric Oxide-Mediated Neurotoxicity
}

\author{
Mirella Gonzalez-Zulueta, ${ }^{1}$ Lisa M. Ensz, ${ }^{1}$ Galina Mukhina, ${ }^{1}$ Russell M. Lebovitz, ${ }^{4}$ Ralf M. Zwacka, ${ }^{5}$ \\ John F. Engelhardt, ${ }^{5}$ Larry W. Oberley, ${ }^{6}$ Valina L. Dawson, ${ }^{1,2,3}$ and Ted M. Dawson ${ }^{1,2}$ \\ Departments of ${ }^{1}$ Neurology, ${ }^{2}$ Neuroscience and ${ }^{3}$ Physiology, Johns Hopkins University School of Medicine, Baltimore, \\ Maryland 21287, ${ }^{4}$ Department of Pathology, Baylor College of Medicine, Houston, Texas 77030, 5 Department of \\ Anatomy and Cell Biology, University of lowa, lowa City, lowa 52232, and ${ }^{6}$ Radiation Research Laboratory, Department of \\ Radiology, University of lowa College of Medicine, lowa City, lowa 52242
}

Neuronal nitric oxide synthase (nNOS) neurons kill adjacent neurons through the action of NMDA-glutamate receptor activation, although they remain relatively resistant to the toxic effects of NMDA and NO. The molecular basis of the resistance of nNOS neurons to toxic insults is unknown. To begin to understand the molecular mechanisms of the resistance of nNOS neurons, we developed a pheochromacytoma-derived cell line (PC12) that is resistant to the toxic effects of NO. We found through serial analysis of gene expression (SAGE) that manganese superoxide dismutase (MnSOD) is enriched in the NO-resistant PC12 cell-derived line (PC12-R). Antisense MnSOD renders $\mathrm{PC} 12-\mathrm{R}$ cells sensitive to $\mathrm{NO}$ toxicity and increases the sensitivity to $\mathrm{NO}$ in the parental, NO-sensitive PC12 line (PC12-S). Adenoviral transfer of MnSOD protects PC12-S cells against NO toxicity. We extended these studies to cortical cultures and showed that MnSOD is enriched in nNOS neurons and that antisense MnSOD renders nNOS neurons susceptible to NMDA neurotoxicity, although it has little effect on the overall susceptibility of cortical neurons to NMDA toxicity. Overexpression of MnSOD provides dramatic protection against NMDA and NO toxicity in cortical cultures, but not against kainate or AMPA neurotoxicity. Furthermore, nNOS neurons from $\mathrm{MnSOD}^{-/-}$mice are markedly sensitive to NMDA toxicity. Adenoviral transfer of MnSOD to $\mathrm{MnSOD}^{-1-}$ cultures restores resistance of nNOS neurons to NMDA toxicity. Thus, MnSOD is a major protective protein that appears to be essential for the resistance of nNOS neurons in cortical cultures to NMDA mediated neurotoxicity.

Key words: nitric oxide; nNOS neuron; MnSOD; NMDA toxicity; resistance to nitric oxide; neurodegenerative diseases
Nitric oxide (NO) is a unique messenger molecule that serves diverse physiological functions throughout the body (Nathan, 1992; Schmidt and Walter, 1994; Garthwaite and Boulton, 1995; Yun et al., 1996). NO is synthesized from L-arginine by NO synthase (NOS). Three isoforms of NOS have been identified and are the products of three distinct genes: neuronal NOS (nNOS, Type I), immunological NOS (iNOS, Type II), and endothelial NOS (eNOS, Type III) (Bredt and Snyder, 1994; Marletta, 1994; Nathan and Xie, 1994). In the nervous system, nNOS is localized to discrete populations of neurons in the cerebellum, cortex, striatum, olfactory bulb, hippocampus, basal forebrain, and brain

Received Oct. 8, 1997; revised Dec. 24, 1997; accepted Dec. 29, 1997.

M.G.-Z. is supported by a postdoctoral research award from the Boehringer Ingelheim Fonds (Stuttgart, Germany). V.L.D. is supported by United States Public Health Service Grant NS33142, the American Heart Association, and the Muscular Dystrophy Association. T.M.D. is an established investigator of the American Heart Association and is supported by United States Public Health Service Grants NS01578 and NS33277, and the Paul Beeson Faculty Scholar Award in Aging Research. We thank Dr. V. Velculescu and Dr. K. Kinzler for providing the SAGE procedure and very helpful advice on SAGE, Dr. Allen Mandir for his assistance with the SAGE software, R. Anderson and Dr. B. L. Davidson for providing adenoviral vectors, and Ann Schmidt for typing assistance.

Under an agreement between Johns Hopkins University and Guilford Pharmaceuticals, T.M.D. and V.L.D. are entitled to a share of sales royalty received by the University from Guilford. T.M.D. and the University also own Guilford stock, and the University stock is subject to certain restrictions under University policy. The terms of this arrangement are being managed by the University in accordance with its conflict of interest policies.

Correspondence should be addressed to Ted M. Dawson, Departments of Neurology and Neuroscience, Johns Hopkins University School of Medicine, $600 \mathrm{~N}$. Wolfe Street, Pathology 2-210, Baltimore, MD 21287.

Copyright (C) 1998 Society for Neuroscience $0270-6474 / 98 / 182040-16 \$ 05.00 / 0$ stem (Bredt et al., 1991; Vincent and Kimura, 1992). Excess production of NO via nNOS has been implicated in various neurotoxic paradigms (Dawson and Snyder, 1994; Dawson and Dawson, 1996; Iadecola, 1997). Excess glutamate acting via NMDA receptors may mediate cell death in focal cerebral ischemia (Choi, 1988; Choi and Rothman, 1990), trauma, and epilepsy, and in neurodegenerative diseases such as Huntington's disease and Alzheimer's disease (Meldrum and Garthwaite, 1990; Lipton and Rosenberg, 1994). In primary cerebral cortical cultures NMDA neurotoxicity is prevented by various NOS inhibitors (for review, see Dawson and Snyder, 1994; Dawson and Dawson, 1996). Evaluation of nNOS inhibitors in various stroke models has shown that selective inhibitors provide dramatic reductions in infarct volume in focal cerebral ischemia (Dalkara and Moskowitz, 1994; Iadecola, 1997; Samdani et al., 1997). In addition, selective nNOS inhibitors provide protection against the dopaminergic neurotoxin 1-methyl-4-phenyl-1,2,3,6-tetrahydropyridine (MPTP) in an animal model of Parkinson's disease (Schulz et al., 1995b; Przedborski et al., 1996) and also provide protection against various mitochondrial neurotoxins (Schulz et al., 1995a).

Because NO is a reactive free radical, it has many potential targets to initiate neurotoxic cascades. A predominant mechanism by which NO may kill neurons is through the diffusionlimited reaction of $\mathrm{NO}$ with superoxide anion $\left(\mathrm{O}_{2}{ }^{\bullet-}\right)$ to generate peroxynitrite $\left(\mathrm{ONOO}^{-}\right)$(Beckman et al., 1990; Beckman, 1994), which is directly cytotoxic (Radi et al., 1991; Beckman and Crow, 1993; Xia et al., 1996). The toxic effects of NO and peroxynitrite may occur through multiple pathways. An important pathway may 
be $\mathrm{NO} / \mathrm{ONOO}^{-}$-damaged DNA and subsequent activation of the enzyme poly(ADP-ribose) polymerase (PARP) (Zhang et al., 1994; Dawson and Dawson, 1996; Eliasson et al., 1997), a nuclear enzyme involved in DNA repair (Lautier et al., 1993). Excessive activation of PARP can rapidly deplete cellular energy stores, leading to cell death. Additionally, NO may elicit neurotoxicity through inhibition of mitochondrial respiration, nitrosylation of proteins, and lipid peroxidation (for review, see Yun et al., 1996).

nNOS neurons are remarkably spared from cell death in NMDA neurotoxicity, Huntington's disease, Alzheimer's disease, and vascular stroke (Thomas and Pearse, 1964; Ferrante et al., 1985; Beal et al., 1986; Koh et al., 1986; Koh and Choi, 1988; Uemura et al., 1990; Hyman et al., 1992; V. L. Dawson et al., 1993). Thus, nNOS neurons must possess protective mechanisms that render them resistant to the toxic NO environment they create. However, the molecular mechanisms that account for the selective resistance of nNOS neurons to neurotoxic insults remain unknown.

NO physiology has been clarified through the study of mice lacking the gene for nNOS (nNOS ${ }^{-1-}$ mice) (Huang et al., 1993). $\mathrm{nNOS}^{-/-}$mice are dramatically resistant to permanent focal ischemia (Huang et al., 1994), MPTP neurotoxicity (Przedborski et al., 1996), and mitochondrial toxins (Schulz et al., 1996). Furthermore, cortical cultures from nNOS ${ }^{-1-}$ mice are resistant to neurotoxicity (Dawson et al., 1996). In the cerebral cortex, all nNOS neurons stain for somatostatin, and almost all somatostatin neurons are nNOS positive (T. M. Dawson et al., 1991). The density of somatostatin-staining neurons is normal in the cerebral cortex of $\mathrm{nNOS}^{-/-}$mice, indicating that although $\mathrm{nNOS}$ has been disrupted, the neurons remain intact. In the mutant mice, somatostatin neurons are spared from NMDA neurotoxicity, indicating that the factors responsible for the selective resistance of nNOS neurons remain intact and probably are not nNOS itself (Dawson et al., 1996). This prompted us to explore further the molecular mechanisms that render nNOS neurons selectively resistant to neurotoxicity.

We elected to study the selective resistance of nNOS neurons to neurotoxicity by developing a PC12 cell-derived line that is resistant to NO-mediated toxicity. We reasoned that $\mathrm{NO}$ resistant and NO-sensitive PC12 cell lines should express different sets of genes, some of which might account for the resistance of the PC-12 cells to NO. To identify these genes, we performed serial analysis of gene expression (SAGE) in NO-resistant and NO-sensitive PC12 cells. We found that manganese superoxide dismutase (MnSOD) is the predominant gene in NO-resistant PC12 cells, and that it is also selectively expressed in cortical nNOS neurons. Strikingly, MnSOD is required for the resistance of nNOS neurons to NMDA and NO-mediated neurotoxicity in cortical cultures.

\section{MATERIALS AND METHODS}

Cell culture. The rat PC12 cell line was maintained in DMEM supplemented with $5 \%$ fetal bovine serum, $10 \%$ horse serum, 2 mm L-glutamine, $100 \mathrm{U} / \mathrm{ml}$ penicillin, and $100 \mathrm{mg} / \mathrm{ml}$ streptomycin. Cells were cultured in a humidified atmosphere of $95 \%$ air and $5 \% \mathrm{CO}_{2}$ at $37^{\circ} \mathrm{C}$.

Primary cortical cell cultures were prepared from gestational day 14 fetal rats or day 16 fetal mice as described previously (V. L. Dawson et al., 1993, 1996). The cortex was dissected under a microscope, incubated for $20 \mathrm{~min}$ in $0.0027 \%$ trypsin and saline solution [5\% PBS (in mM) 40 sucrose, 30 glucose, 10 HEPES, pH 7.4]. Rat cortex was transferred to modified Eagle's medium (MEM), $10 \%$ horse serum, $10 \%$ fetal bovine serum, and $2 \mathrm{~mm}$ glutamine, and cells were dissociated by trituration. Mouse cortex was dissected and the cells were dissociated by trituration in MEM, 20\% horse serum, $25 \mathrm{~mm}$ glucose, and $2 \mathrm{mM}$ L-glutamine after a 30 min digestion in $0.027 \%$ trypsin and saline solution (Life Technologies, Gaithersburg, MD). Cells were plated in $15 \mathrm{~mm}$ multiwell (Nunc, Roskilde, Denmark) plates coated with polyornithine at a density of $3-4 \times 10^{5}$ cells per well. Four days after they were plated, the cells were treated with $10 \mu \mathrm{g} / \mathrm{ml}$ of 5-fluoro-2'-deoxyuridine for $3 \mathrm{~d}$ to inhibit proliferation of non-neuronal cells. Rat cultures were maintained in MEM, 5\% horse serum, and $2 \mathrm{mM}$ glutamine in $8 \% \mathrm{CO}_{2}$, humidified, $37^{\circ} \mathrm{C}$ atmosphere. Murine cultures were maintained in MEM, $10 \%$ horse serum, $25 \mathrm{~mm}$ glucose, and $2 \mathrm{mM}$ L-glutamine in a $5 \% \mathrm{O}_{2}, 8 \% \mathrm{CO}_{2}$, humidified, $37^{\circ} \mathrm{C}$ incubator. The medium was changed twice a week. Mature neurons (14 $\mathrm{d}$ in culture) were used for all experiments. In mature cultures, neurons represent $70-90 \%$ of the total number of cells (V. L. Dawson et al., 1993, 1996).

Cytotoxicity. Cells were exposed to test solutions as described previously (V. L. Dawson et al., 1991). Cells were washed with control salt solution (CSS) containing (in mM) $120 \mathrm{NaCl}, 5.4 \mathrm{KCl}, 1.8 \mathrm{CaCl}_{2}, 25$ Tris-HCl, 15 glucose, $\mathrm{pH}$ 7.4. Except for kainate, all other drugs were applied in CSS for 5 min. Kainate was applied in MEM, $21 \mathrm{~mm}$ glucose for $24 \mathrm{hr}$ in the incubator. Toxicity was assayed $20-24 \mathrm{hr}$ after exposure to drug solutions by trypan blue exclusion as described (V. L. Dawson et al., 1993). Three to five photoprints at $10-20 \times$ were made of each well. Live cells (cells that exclude trypan blue) and dead cells (cells that take up trypan blue) were counted, and the percentage of cell death was determined. Approximately 500-1200 cells were counted per well. At least two separate experiments using three different wells were performed so that $\sim 3000-7200$ neurons were counted for each data point. To assess rater reliability, some of the photomicrographs were counted by an additional observer blinded to the study design and treatment protocol. An inter-rater consistency $>95 \%$ was observed for the cell counting.

In some experiments toxicity was assayed $20-24 \mathrm{hr}$ after exposure to cytotoxic conditions by microscopic examination with computer-assisted cell counting after staining of all nuclei with $1 \mu \mathrm{g} / \mathrm{ml}$ Hoescht 33342 and staining of dead cell nuclei with $7 \mu \mathrm{M}$ propidium iodide. Total and dead cells were counted. Glial nuclei fluoresce at a different intensity then neuronal nuclei and were gated out. The percentage of cell death was determined as the ratio of live to dead cells as compared with the percentage of cell death in control wells to account for cell death attributed to mechanical stimulation of the cultures. At least two separate experiments using four separate wells were performed with a minimum of 15,000-20,000 neurons counted per data point. All reagents were purchased from Sigma (St. Louis, MO).

Data were analyzed with the Student's $t$ test for independent means. Statistical analyses were performed by using StatView 4.0 software (Abacus Concepts, Calabasas, CA).

Antisense oligonucleotides. Phosphorothioate oligodeoxynucleotides (Soligodeoxynucleotides) in which all phosphodiester linkages were modified were synthetized, lyophilized, diluted in sterile water, and stored at $-20^{\circ} \mathrm{C}$. Oligonucleotides were chosen, purified, and used according to standard procedures (Bito et al., 1996; Rothstein et al., 1996). Oligonucleotides were chosen to exhibit minimal self-complementarity according to analysis with the computer program OLIGO 4 (National Biosciences, Plymouth, MN). All sequences chosen were specific and unrelated to any other nucleotide sequence in GenBank. The sequence for the antisense oligonucleotide to rat MnSOD used is $5^{\prime}$-CCCGACACAACATTGCTGA-3', and it spans from six bases $5^{\prime}$ to 10 bases $3^{\prime}$ of the start codon. Control cultures received either no oligonucleotide or sense or random oligonucleotide (in which the base composition and extent of phosphodiester linkages were identical to that of the antisense oligonucleotide but the sequence was randomly assigned). Oligonucleotides were reconstituted in serum-free medium and filtered before addition to the cultures.

Infection of cultured cells with recombinant adenovirus. Primary cortical cells were maintained in culture for $14 \mathrm{~d}$ before being exposed to the adenoviral vector. PC12 cells were cultured to $90 \%$ confluence in 24-well plates. Cultures were exposed to $1 \times 10^{8} \mathrm{pfu} / \mathrm{ml}\left(1 \times 10^{10}\right.$ particles $\left./ \mathrm{ml}\right)$ of adenoviral vector for $1 \mathrm{hr}$ in $0.5 \mathrm{ml}$ of serum-free medium, followed by overnight incubation in $0.5 \mathrm{ml}$ of $2 \%$ serum-containing medium in the presence of $1 \times 10^{8} \mathrm{pfu} / \mathrm{ml}$ of adenoviral vector. In this system (Ad.MnSOD), MnSOD gene transcription is under the control of the strong cytomegalovirus (CMV) promoter (R. M. Zwacka and J. F. Engelhardt, unpublished data). After overnight incubation with Ad.MnSOD in $2 \%$ serum-containing medium, $0.5 \mathrm{ml}$ of $10 \%$ serum-containing medium was added to each well. Cells were cultured for an additional $24 \mathrm{hr}$ to allow protein expression before any additional experiment or analysis was performed. Noninfected cells and cells exposed to a $\beta$-galactosidase- 
containing adenoviral vector (Ad. $\beta \mathrm{Gal}$ ) were included as controls. Ad. $\beta$ Gal also contains the $\beta$-galactosidase gene under the CMV promoter and allowed us to monitor the infection efficiency after X-Gal staining of adenovirus-exposed cells. Briefly, $24 \mathrm{hr}$ after exposure to $1 \times$ $10^{8} \mathrm{pfu} / \mathrm{ml}$ of Ad. $\beta \mathrm{Gal}$, cells were fixed for $10 \mathrm{~min}$ at room temperature with $0.5 \%$ glutaraldehyde and stained with 5-bromo-4-chloro-3-indolyl$\beta$-D-galactopyranoside (X-Gal) solution for $2 \mathrm{hr}$ in a $37^{\circ} \mathrm{C}$, non- $\mathrm{CO}_{2}$ incubator.

Western blot analysis. For protein analysis, culture plates were rinsed twice with cold PBS, pH 7. Cells were scraped and harvested in cold PBS, centrifuged at $2500 \mathrm{rpm}$, and resuspended in PBS. Cells were then sonicated on ice for a total of $2 \mathrm{~min}$ at $60 \%$ duty cycle and output level 2 , using a Branson sonifier. Cell extracts were stored at $-70^{\circ} \mathrm{C}$. Total protein was assayed using the Bradford method (Pierce, Rockford, IL). Proteins in cell lysates were size-separated through denaturing polyacrylamide gel electrophoresis (SDS-PAGE). An equal amount of protein for each sample was heated at $100^{\circ} \mathrm{C}$ for $5 \mathrm{~min}$ with an equivalent volume of $2 \times$ sample buffer (containing $4 \%$ SDS and $10 \% \beta$-mercaptoethanol) and loaded onto $12 \%$ polyacrylamide gels. The proteins were electrotransferred to a nitrocellulose membrane in tris-glycine-methanol buffer. The membrane was blocked for $1 \mathrm{hr}$ at room temperature in a blocking solution mixture of $3 \%$ nonfat dry milk, $0.05 \%$ Tween-20, and Trisbuffered saline (TBS), pH 8.0. The membrane was then incubated for 1 $\mathrm{hr}$ at room temperature with primary antibody in blocking solution (rabbit anti-MnSOD serum diluted 1:3000; rabbit anti-CuZnSOD serum diluted 1:3000; rabbit anti-nNOS serum diluted 1:2000; anti- $\beta$-tubulin monoclonal diluted 1:10,000). All primary antibodies are previously characterized antibodies that recognize a single band on Western blot analysis (Oberley et al., 1990; Roskams et al., 1991). The membrane was rinsed with blocking solution for five washes of $5 \mathrm{~min}$ and incubated for $1 \mathrm{hr}$ at room temperature in a 1:10,000 dilution of goat anti-rabbit IgG peroxidase-labeled antibody (Boehringer Mannheim, Indianapolis, IN), or goat anti-mouse IgG peroxidase-labeled antibody (Jackson ImmunoResearch Laboratories, West Grove, PA). The blot was washed $5 \times 5$ min and then processed for analysis using an Enhanced ChemiLuminiscence (ECL) detection kit (Kirkegaard and Perry Laboratories, Gaithersburg, MD) as described by this manufacturer.

MnSOD activity assay. MnSOD activity was assayed as described (Spitz and Oberley, 1989). In brief, a competitive inhibition assay was performed that used xanthine-xanthine oxidase-generated $\mathrm{O}_{2}{ }^{\bullet-}$ to reduce nitroblue tetrazolium (NBT) to blue formazan. Reduction of NBT was monitored spectrophotometrically at $560 \mathrm{~nm}$. The amount of protein that inhibits NBT reduction to $50 \%$ of maximum is defined as $1 \mathrm{U}$ of MnSOD activity. In this assay CuZnSOD is inhibited by $5 \mathrm{~mm}$ sodium cyanide. Enzymatic activity was expressed in units per milligram of protein.

NADPH-diaphorase staining. Cells were washed three times with CSS and fixed for $30 \mathrm{~min}$ at $4^{\circ} \mathrm{C}$ in a $4 \%$ paraformaldehyde (PF), $0.1 \mathrm{M}$ phosphate buffer (PB). Fixative solution was washed away with TBS, and reaction solution was applied for $1 \mathrm{hr}$ at $37^{\circ} \mathrm{C}$. The reaction solution contains $1 \mathrm{~mm}$ NADPH, $0.2 \mathrm{~mm}$ nitroblue tetrazolium, $0.2 \%$ Triton $\mathrm{X}-100,1.2 \mathrm{~mm}$ sodium azide, and $0.1 \mathrm{M}$ Tris- $\mathrm{HCl}, \mathrm{pH}$ 7.2. The reaction was terminated by washing away the reaction solution with TBS. All diaphorase-positive cells in each well were counted by using an inverted microscope.

Immunofluorescence. Cultured cells were washed three times with CSS and fixed for $30 \mathrm{~min}$ at $4^{\circ} \mathrm{C}$ in a $4 \% \mathrm{PF}, 0.1 \mathrm{M} \mathrm{PB}$. The cells were then washed in TBS and permeabilized with $0.2 \%$ Triton X-100 in TBS for 5 min. Blocking solution containing $5 \%$ normal goat serum (NGS), $0.1 \%$ Triton X-100 in TBS was then applied for $1 \mathrm{hr}$ at room temperature. Primary antibodies to nNOS (monoclonal), MnSOD (polyclonal), or $\mathrm{CuZnSOD}$ (polyclonal) were diluted in blocking solution and applied to the cells overnight at $4^{\circ} \mathrm{C}$. After rinsing the cells three times with TBS, fluorescence-conjugated secondary antibodies (fluorescein, FITCconjugated anti-mouse $\mathrm{IgG}$, or lissamine rhodamine-conjugated antirabbit IgG; Jackson ImmunoResearch) were applied in $1.5 \%$ NGS, TBS, $0.1 \%$ Triton X-100 for $1 \mathrm{hr}$ at room temperature. After an additional three washes in TBS, cells were examined under a fluorescence microscope. Control cells lacking primary or secondary antibody were stained in parallel and failed to exhibit any immunostaining.

Southern blot and PCR analysis. Genotyping was performed by Southern blot analysis of genomic DNA from $14 \mathrm{~d}$ embryos as described by Lebovitz et al. (1996). The PCR approach was also used to determine MnSOD genotype of embryos and cortical cultures. Oligonucleotide primers were designed for specific amplification of exon 2 of the mouse MnSOD gene, and the human hypoxanthine phosphoribosyltransferase
(HPRT) minigene was used to target exons 1 and 2 of MnSOD. PCR amplification of MnSOD was performed in a final volume of $25 \mu \mathrm{l}$, containing $1 \mu \mathrm{M}$ each oligonucleotide primer (5'-ACA AGC ACA GCC TCC CAG AC-3' and 5'-AGC CTC GTG GTA CTT CTC CTC-3' ), 200 $\mu \mathrm{M}$ deoxynucleotides, $10 \mathrm{~mm}$ Tris- $\mathrm{HCl}$, pH 8.3, $50 \mathrm{~mm} \mathrm{KCl}, 1.5 \mathrm{~mm}$ $\mathrm{MgCl}_{2}, 0.01 \%$ gelatin, $1 \mathrm{U}$ of Taq DNA polymerase (Boehringer Mannheim), and $2.5 \%$ DMSO. Twenty-six cycles of $94^{\circ} \mathrm{C}$ for $1 \mathrm{~min}, 62^{\circ} \mathrm{C}$ for 45 sec, and $72^{\circ} \mathrm{C}$ for $30 \mathrm{sec}$ were performed with an initial denaturation step of $94^{\circ} \mathrm{C}$ for $3 \mathrm{~min}$ and a final elongation step at $72^{\circ} \mathrm{C}$ for $1 \mathrm{~min}$. PCR products were resolved on $3 \%$ agarose gels. Amplifications of human HPRT were performed as described for the MnSOD gene except for the primer sequences: 5'-GCT GAG GAT TTG GAA AGG G-3' and 5'-TTG CAG CCT TGA CCA TCT T-3', and an annealing temperature of $55^{\circ} \mathrm{C}$.

\section{RESULTS}

\section{Generation of a NO-resistant PC12 cell line}

A brief ( $5 \mathrm{~min}$ ) application of NO donors effectively causes death of cultured primary cortical neurons 20-24 hr later (V. L. Dawson et al., 1991). In an attempt to identify a cell line that would be reflective of NO-mediated cell death in cortical neuronal cultures, we screened a number of tumor cell lines for susceptibility to a 5 min exposure to NO donors as assessed $24 \mathrm{hr}$ later (V. L. Dawson and T. M. Dawson, unpublished observations). Rat PC12 cells are remarkably sensitive to the toxic effects of NO donors (Fig. $1 A$ ). A 5 min application of the NO donor sodium nitroprusside (SNP), elicits $\sim 45 \%$ cell killing at $500 \mu \mathrm{M}$, and almost $90 \%$ cell death at $1 \mathrm{~mm}$ as assessed $24 \mathrm{hr}$ later. SNP that is depleted of NO by overnight incubation in buffer under light elicits no toxicity (data not shown).

In a manner analogous to that described by Edwards and colleagues (Liu et al., 1992) in which they identified the vesicular catecholamine transporter responsible for the resistance of a PC12 cell-derived line to MPP+, we reasoned that the development of a NO-resistant PC12 cell line would be useful in the identification of genes that confer resistance to NO-mediated toxicity. A NO-resistant PC12 cell line (PC12-R) was generated by treating parental PC12 cell cultures (PC12-S) with $100 \mu \mathrm{M}$ SNP for $5 \mathrm{~min}$ and allowing the surviving cells to grow to confluence, followed by successive retreatments with incremental doses of SNP until a cell line (PC12-R) was generated that was resistant to $1 \mathrm{~mm}$ SNP (Fig. 1A). The PC12-R cells are also remarkably resistant to high doses of other NO donors such as diethylenetriamine nitric oxide adduct (DETA/NO) and 3-morpholinosydnonimine hydrochloride (SIN-1) (Fig. 1 $A$ ). DETA/NO and SIN-1 that were depleted of NO by overnight incubation in buffer under light elicit no toxicity (data not shown).

\section{MnSOD protein and activity levels are elevated in NO- resistant PC12 cells}

Kinzler and colleagues (Velculescu et al., 1995) recently developed an elegant method called serial analysis of gene expression (SAGE) that allows the quantitative and simultaneous analysis of a large number of transcripts in a given cell population. SAGE provides a means for the quantitative cataloging and comparison of expressed genes in various normal, developmental, and diseased states (Velculescu et al., 1995). We used SAGE to identify genes that could account for the resistance of the PC12-R cell line to NO. More than 4000 transcripts were analyzed from PC12-S and PC12-R cell lines (M. Gonzalez-Zulueta, V. L. Dawson, and T. M. Dawson, unpublished observations). More than 100 transcripts were expressed at higher levels in the PC12-R cell population than in the PC12-S cell population. One of the most highly differentially expressed transcripts in PC12-R cells corresponded 
A

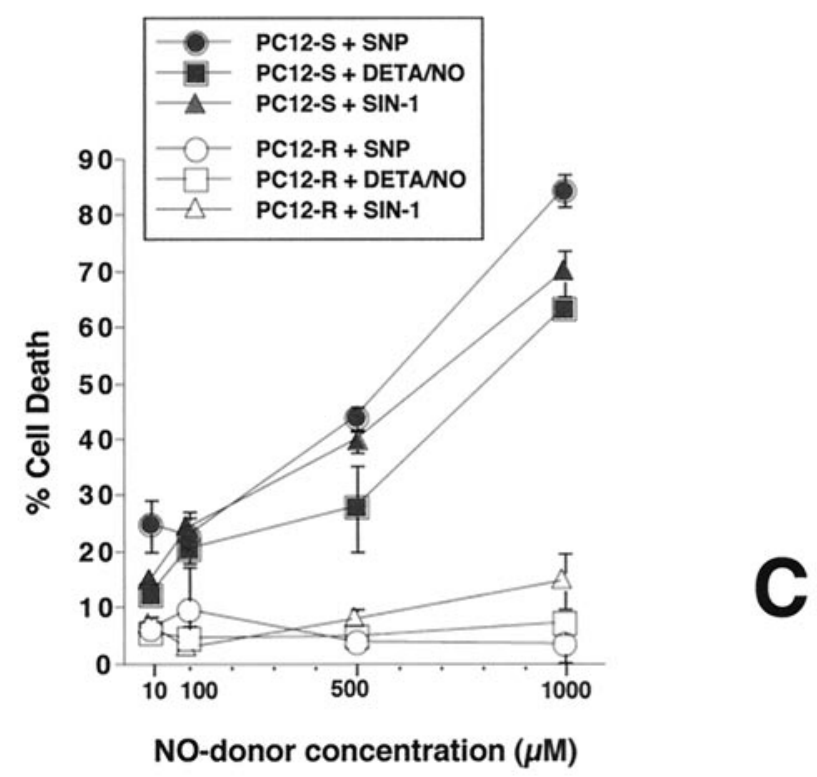

\begin{tabular}{ccc}
\hline \multirow{2}{*}{$\begin{array}{c}\text { SAGE } \\
\text { Tag }\end{array}$} & \multicolumn{2}{c}{ Abundance (\%) } \\
\cline { 2 - 3 } & PC12-R Library & PC12-S Library \\
\hline CAGCTGCACC & 1.5 & 0.5 \\
\hline
\end{tabular}

MnSOD cDNA: nucleotides 1 to 240

1 gcgcctcagc aatgttgtgt cgggcggcgt gcagcgcggg cagaagactg ggccccgcgg

61 ccagtaccgc gggctcccgg cacaagcaca gcctccctga cctgccttac gactatggcg

121 cgctggagcc gcacattaac gcgcagatca tgcagctgca ccacagcaag caccacgcga

181 cctacgtgaa caatctgaac gtcaccgagg agaagtacca cgaggcgctg gccaagggag

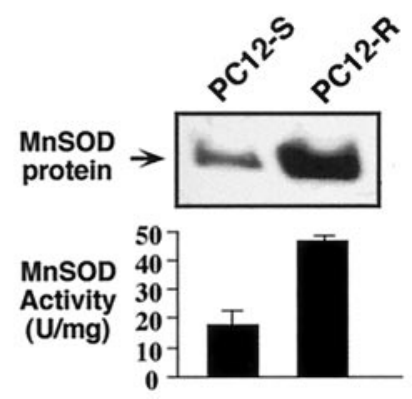

Figure 1. Characterization of PC12-R cells: resistance to NO toxicity and increased expression of MnSOD. A, Susceptibility of PC12-S and PC12-R cells to the NO donors sodium nitroprusside (SNP), diethylenetriamine nitric oxide adduct (DETA/NO), and 3-morpholino-sydnonimine hydrochloride (SIN-1). Cells were exposed to the NO donors for $5 \mathrm{~min}$, and cytotoxicity was assayed $24 \mathrm{hr}$ later by trypan blue exclusion. The wild-type PC12 line (PC12-S) is remarkably sensitive to the toxic effects of NO. An NO-resistant PC12 cell line (PC12-R) was generated by treating parental PC12-S cells with $100 \mu \mathrm{M} \mathrm{SNP}$ for $5 \mathrm{~min}$, allowing the surviving cells to grow to confluence followed by successive retreatments with incremental doses of SNP until a cell line (PC12-R) was generated that was resistant to 1 mM SNP. B, Predominant differentially expressed SAGE tag in PC12-R compared with PC12-S cell populations corresponds to MnSOD. This specific tag sequence, its abundance in each tag library analyzed, and its location in the MnSOD cDNA sequence is indicated. $C$, Western blot and catalytic activity analyses of MnSOD in PC12-S and PC12-R cells indicate that MnSOD levels are increased in PC12-R when compared with PC12-S. For Western blot analysis, $10 \mu \mathrm{g}$ total protein was loaded in each lane and electrophoresed under denaturing conditions on a $12 \%$ polyacrylamide gel. MnSOD was detected as an apparent $23 \mathrm{kDa}$ protein band with a rabbit polyclonal antibody raised against MnSOD (Oberley et al., 1990). MnSOD activity was measured using the nitroblue tetrazolium method of Oberley and Spitz (1985) as later modified. Data represents the mean \pm SEM of two to three independent experiments. Western blots are representative of two to three independent experiments.

to the mRNA for manganese superoxide dismutase (MnSOD) (Fig. $1 B$ ). Because of the role of MnSOD in cellular antioxidant defense, we elected to focus our initial attention on the potential protective role of MnSOD against NO toxicity. We analyzed MnSOD protein levels in the PC12-S and PC12-R cell lines via Western blot analysis as well as MnSOD catalytic activity (Fig. $1 C)$. Confirming the SAGE analysis, we show that MnSOD protein and activity levels are elevated dramatically in PC12-R cells compared with PC12-S cells.

\section{Antisense MnSOD increases susceptibility to NO- toxicity in PC12 cells}

To investigate the potential role of MnSOD as a neuroprotective protein against NO-mediated toxicity in PC12 cells, we developed an antisense oligonucleotide approach to knock down MnSOD protein levels and catalytic activity (Fig. 2), following standard and well characterized procedures for neuronal cells (Bito et al., 1996; Rothstein et al., 1996). Consistent with the observations that PC12-S cells contain significantly less MnSOD than PC12-R cells, $2.5 \mu \mathrm{M}$ antisense oligonucleotide to MnSOD completely eliminates MnSOD protein levels and catalytic activity in PC12-S cells, whereas $10 \mu \mathrm{M}$ antisense oligonucleotide is required to abolish MnSOD protein levels and catalytic activity in the PC12-R cell line (Fig. 2A). Exposure of PC12-S and PC12-R cells to antisense oligonucleotide to MnSOD is not associated with a decrease in cell viability (data not shown). The superoxide anion is scavenged by a family of SOD enzymes (McCord, 1969; Fridovich, 1986; Bannister et al., 1987; Hassan, 1988; Fridovich, 1995). In eukaryotic cells, the copper-zinc ( $\mathrm{CuZn}$ ) SOD isoform is found mainly in the cytosol, whereas the MnSOD is located in the mitochondria. The amount of CuZnSOD in the PC12-R cell line is equivalent to that in the PC12-S cell line as assessed by Western blot analysis (Fig. 2A), which indicates that CuZnSOD probably does not account for the resistance of the PC12-R cells to NO toxicity. Furthermore, the antisense oligonucleotide to MnSOD did not affect CuZnSOD protein levels (Fig. $2 A$ ), indicating that our antisense knockdown approach is specific for MnSOD and that it does not affect the expression of other constitutively expressed proteins. In the PC12-R cells, $10 \mu \mathrm{M}$ antisense oligonucleotide significantly reduces MnSOD protein levels after $24 \mathrm{hr}$ of exposure (Fig. 2B). Thus, in all future studies 

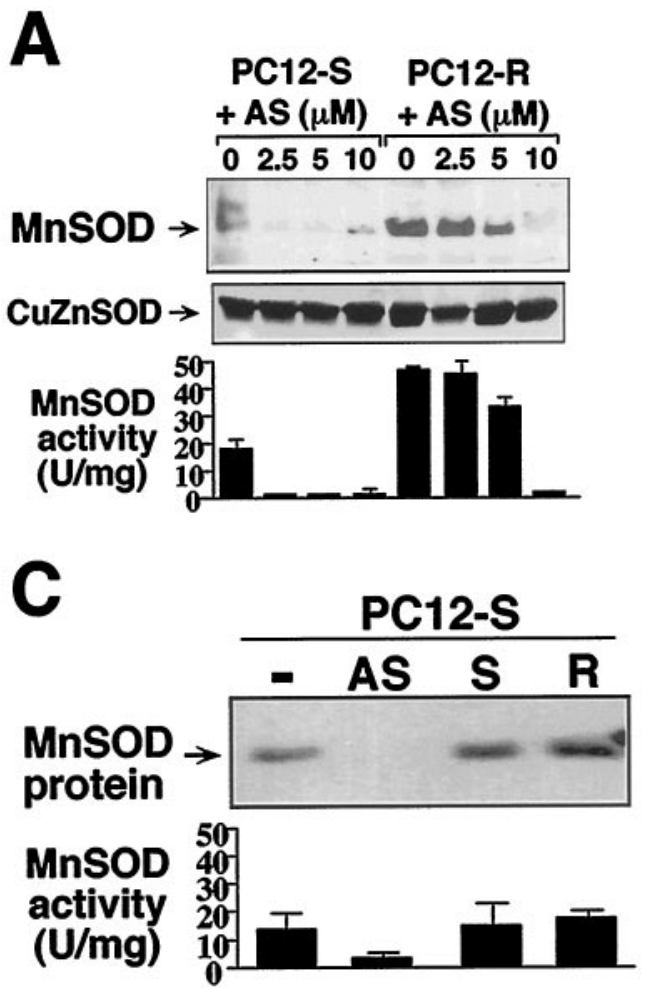

B
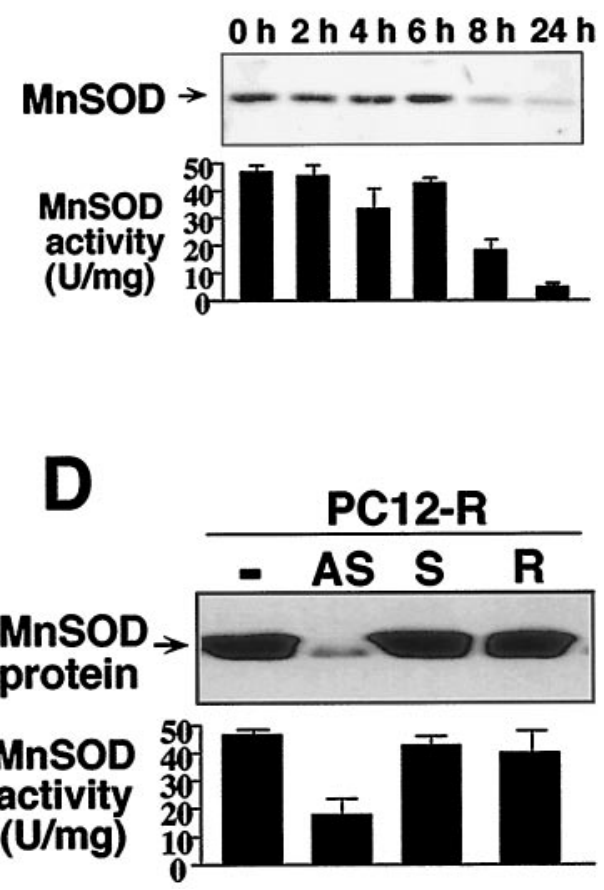

Figure 2. Antisense oligonucleotide knockdown of MnSOD in PC12 cells. A, Dose-response of MnSOD protein and activity levels to antisense oligonucleotide to MnSOD. PC12-S and PC12-R cells were exposed to increasing concentrations of antisense oligonucleotides $(A S)$ for 24 hr. After 24 $\mathrm{hr}$ in the presence of AS, cells were harvested for Western blot and activity analyses. For Western blot analysis, $10 \mu \mathrm{g}$ of total protein was loaded in each lane. Antibodies against MnSOD detected an apparent $23 \mathrm{kDa}$ protein band, and antibodies against CuZnSOD detected a $16 \mathrm{kDa}$ protein band. $B$, MnSOD protein and activity levels in PC12-R cells over $24 \mathrm{hr}$ in the presence of AS oligonucleotide to MnSOD. PC12-R cells were exposed to $10 \mu \mathrm{M}$ AS oligonucleotide and harvested at the time points indicated after addition of the oligonucleotide. For Western blot analysis, $5 \mu \mathrm{g}$ of total protein was loaded in each lane. $C, D$, Downregulation of MnSOD protein and activity levels in $(C)$ PC12-S and $(D)$ PC12-R cells is specific to AS oligonucleotide treatment. Cells were exposed for $24 \mathrm{hr}$ to either no oligonucleotide $(-)$, antisense oligonucleotide to MnSOD $(A S)$, sense oligonucleotide $(S)$, or random oligonucleotide $(R) ; 5 \mu \mathrm{M}$ each oligonucleotide was used to treat PC12-S cells, and $10 \mu \mathrm{M}$ each oligonucleotide was used for PC12-R. Ten micrograms of total protein were loaded in each lane for Western blot analysis. Western blots are representative of two to three independent experiments. Data represents the mean \pm SEM of two to three independent experiments.

antisense oligonucleotides to MnSOD were applied for $24 \mathrm{hr}$ at a concentration of $10 \mu \mathrm{M}$. Exposure to sense and random oligonucleotides did not show any effect on MnSOD protein and activity levels in PC12-S and PC12-R cells, confirming the specificity of our antisense knockdown experiments (Fig. 2C,D). Exposure of $\mathrm{PC} 12-\mathrm{R}$ cells to the antisense oligonucleotide resulted in reduction of both MnSOD protein and catalytic activity to levels similar to those present in control PC12-S cells.

To test our hypothesis that MnSOD accounts for the resistance of the PC12-R cell line to NO mediated toxicity, we used antisense oligonucleotides to knock down MnSOD activity in PC12-S and PC12-R cells and exposed them to increasing concentrations of the NO donor SNP (Fig. 3A,B). Exposure of the PC12-S line to antisense oligonucleotide to MnSOD dramatically increases the sensitivity of these cells to SNP (Fig. $3 A)$. SNP $(10 \mu \mathrm{M})$ elicits minimal toxicity in $\mathrm{PC} 12-\mathrm{S}$ cells, but in the presence of antisense oligonucleotide to MnSOD 50\% of the cells die. SNP $(100 \mu \mathrm{M})$ causes $\sim 20 \%$ cell death in PC12-S cells and $\sim 90 \%$ cell death in antisense-treated cells (Fig. $3 A$ ). In the PC12-R line, exposure to antisense oligonucleotide to MnSOD restores the sensitivity of these cells to SNP toxicity (Fig. 3B). Sense and random oligonucleotides with equivalent levels of sulfation have minimal effects on the susceptibility of both PC12-S and PC12-R lines to SNP. Knockdown of MnSOD via antisense oligonucleotides also cor- relates with an increased susceptibility of both $\mathrm{PC12}-\mathrm{S}$ and PC12-R lines to another NO donor, DETA/NO. In PC12-S cells, $10 \mu \mathrm{M}$ DETA/NO elicits $\sim 20 \%$ cell death, whereas in the presence of antisense MnSOD oligonucleotides DETA/NO-induced cell death is increased to $\sim 50 \%$ (Fig. $3 C$ ). In the PC12-R line, 1 mM DETA/NO causes $\sim 10 \%$ cell death, and this proportion is increased to $80 \%$ when cells are exposed to antisense oligonucleotides (Fig. 3D).

Because the toxic effects of NO are thought to occur mainly through an interaction with $\mathrm{O}_{2}^{\bullet-}$, we examined the effect of $\mathrm{O}_{2}^{\bullet-}$ - generating compounds on cells exposed to antisense MnSOD oligonucleotide (Fig. 4). PC12-R cells are twofold more resistant than PC12-S cells to the toxic effects of $500 \mu \mathrm{M}$ paraquat and $500 \mu \mathrm{M}$ menadione. The resistance of PC12-R cells to paraquat and menadione toxicity is not as profound as their resistance to NO generators (compare Fig. 3B,D with Fig. 4B,D). Antisense knockdown of MnSOD increases the susceptibility of PC12-S cells and PC12-R cells to paraquat and menadione by $1.5-$ to twofold (Fig. 4). This increase is not as dramatic as the three- to eightfold increase in susceptibility to NO donors. Thus, although MnSOD may play a role in the cellular defense against excess $\mathrm{O}_{2}{ }^{\bullet-}$, it appears to be critical in the protective pathways against NO-mediated cellular injury. 

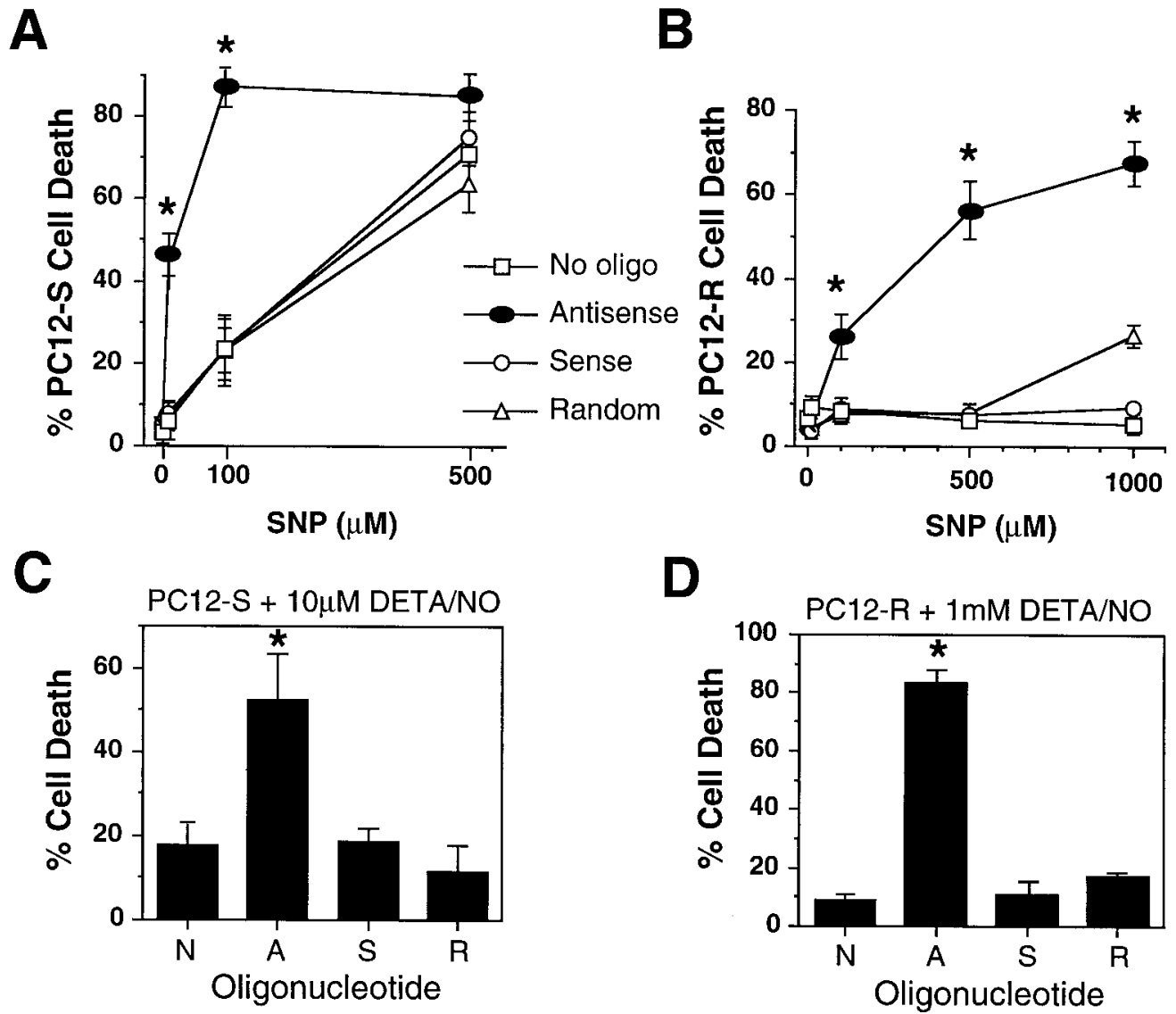

Figure 3. Antisense MnSOD increases susceptibility to NO toxicity in PC12 cells. A, Effect of oligonucleotides to MnSOD on PC12-S sensitivity to SNP. Antisense, sense, or random oligonucleotide (5 $\mu \mathrm{M}$ each) were added to PC12-S. After $24 \mathrm{hr}$, cells were treated with 10, 100, and 500 $\mu \mathrm{M} \mathrm{SNP} \mathrm{for} 5 \mathrm{~min}$, and the medium replaced with fresh oligonucleotide. Twenty-four hours later, toxicity was assessed by trypan blue exclusion. $B$, Effect of oligonucleotides to MnSOD on PC12-R susceptibility to SNP. Experiments were performed as described for PC12-S, with the exception that $10 \mu \mathrm{M}$ each oligonucleotide was used and the highest SNP concentration tested was $1 \mathrm{~mm}$. $C$, Effect of oligonucleotides to MnSOD on PC12-S sensitivity to $10 \mu \mathrm{M}$ DETA/NO. The experiment was performed as in $A$, with the exception that only one dose $(10 \mu \mathrm{M})$ of DETA/NO was tested. $D$, Effect of oligonucleotides to MnSOD on PC12-R susceptibility to $1 \mathrm{~mm}$ DETA/NO. The experiment was performed as in $B$, with the exception that only one dose (1 mM) of DETA/NO was tested. Data represents the mean \pm SEM of two to three independent experiments. ${ }^{*} p<0.001$.

\section{Overexpression of MnSOD confers resistance to NO toxicity in PC12 cells}

To further support our hypothesis that MnSOD accounts for the resistance of the PC12-R line to NO-mediated toxicity, we overexpressed MnSOD in PC12 cells via an adenovirus-derived vector containing the gene for MnSOD (Ad.MnSOD) (Fig. 5). PC12-S and PC12-R cells were exposed to $10^{8} \mathrm{pfu} / \mathrm{ml}$ of Ad.MnSOD or to an adenovirus containing the reporter gene $\beta$-galactosidase (Ad. $\beta$ Gal). Infection with Ad.MnSOD dramatically increases MnSOD protein levels and MnSOD catalytic activity in PC12-S cells (Fig. 5A). PC12 cells transfected with Ad. $\beta$ Gal and Ad.MnSOD maintain a normal morphological appearance and remain viable, as demonstrated by the absence of trypan blue staining (data not shown). Ad.MnSOD has little effect on MnSOD protein and catalytic activity in PC12-R, which may be caused by the already high levels of MnSOD in this cell line (Fig. $5 A)$. The control Ad. $\beta$ Gal virus has no effect on MnSOD levels in PC12-S or PC12-R cells.

Overexpression of MnSOD in PC12-S cells renders them almost completely resistant to the toxic effects of $1 \mathrm{~mm} \mathrm{SNP,} \mathrm{which}$ is equivalent to the resistance of PC12-R cells to $1 \mathrm{~mm} \mathrm{SNP} \mathrm{(Fig.}$ $5 B)$. The Ad. $\beta$ Gal virus has no significant effects on the suscep- tibility of PC12-S or PC12-R to SNP. Similar results were obtained with DETA/NO (data not shown). Overexpression of MnSOD provides some protection against $\mathrm{O}_{2}{ }^{\bullet-}$ - generating compounds. Paraquat $(1 \mathrm{~mm})$ causes $100 \%$ cell death in uninfected PC12-S cells, but only $40 \%$ cell death in cells overexpressing MnSOD (Fig. 5C). Similar results were obtained with menadione (data not shown). This contrasts with the nearly complete protection provided by Ad.MnSOD against NO donor toxicity. Ad.MnSOD had no effect on the susceptibility of PC12-R cells to $\mathrm{NO}$ donors or $\mathrm{O}_{2}^{\bullet-}$-generating compounds (data not shown), which correlates with the high levels of MnSOD protein and remarkable resistance to $\mathrm{NO}$ and $\mathrm{O}_{2}{ }^{\bullet-}$ of these cells before infection.

\section{MnSOD is selectively enriched in nNOS neurons}

Because increased levels of MnSOD may account for the resistance of the PC12-R line to NO-mediated toxicity, this prompted us to investigate the potential protective role of MnSOD in nNOS neurons. nNOS neurons in primary cortical cultures comprise $\sim 1-2 \%$ of the total neuronal population (Bredt et al., 1991). Strikingly, MnSOD is enriched in nNOS neurons, as indicated by immunohistochemical colocalization studies (Fig. 6A-I). In con- 
Figure 4. Effect of MnSOD knockdown on PC12 sensitivy to superoxide generators. $A$, Effect of oligonucleotides to MnSOD on PC12-S sensitivity to paraquat. Antisense, sense, or random oligonucleotides (5 $\mu \mathrm{M}$ each) were added to PC12-S. After $24 \mathrm{hr}$, cells were treated with 10,100 , and $500 \mu \mathrm{M}$ paraquat for $5 \mathrm{~min}$, and the medium was replaced with fresh oligonucleotide. Twenty-four hours later, toxicity was assessed by trypan blue exclusion. $B$, Effect of oligonucleotides to MnSOD on PC12-R susceptibility to paraquat. Experiments were performed as described for PC12-S, with the exception that 10 $\mu \mathrm{M}$ each oligonucleotide was used, and the highest paraquat concentration tested was $1 \mathrm{~mm}$. $C$, Effect of oligonucleotides to MnSOD on PC12-S sensitivity to menadione. Antisense, sense, or random oligonucleotides (5 $\mu \mathrm{M}$ each) were added to PC12-S. After $24 \mathrm{hr}$, cells were treated with 10,100 , and $500 \mu \mathrm{M}$ and 1 $\mathrm{mm}$ menadione for $5 \mathrm{~min}$, and the medium replaced with fresh oligonucleotide. Twenty-four hours later, toxicity was assessed by trypan blue exclusion. $D$, Effect of oligonucleotides to MnSOD on PC12-R susceptibility to menadione. Experiments were performed as described for PC12-S, with the exception that $10 \mu \mathrm{M}$ each oligonucleotide was used. Data represents the mean \pm SEM of two to three independent experiments. ${ }^{*} p<0.001$.
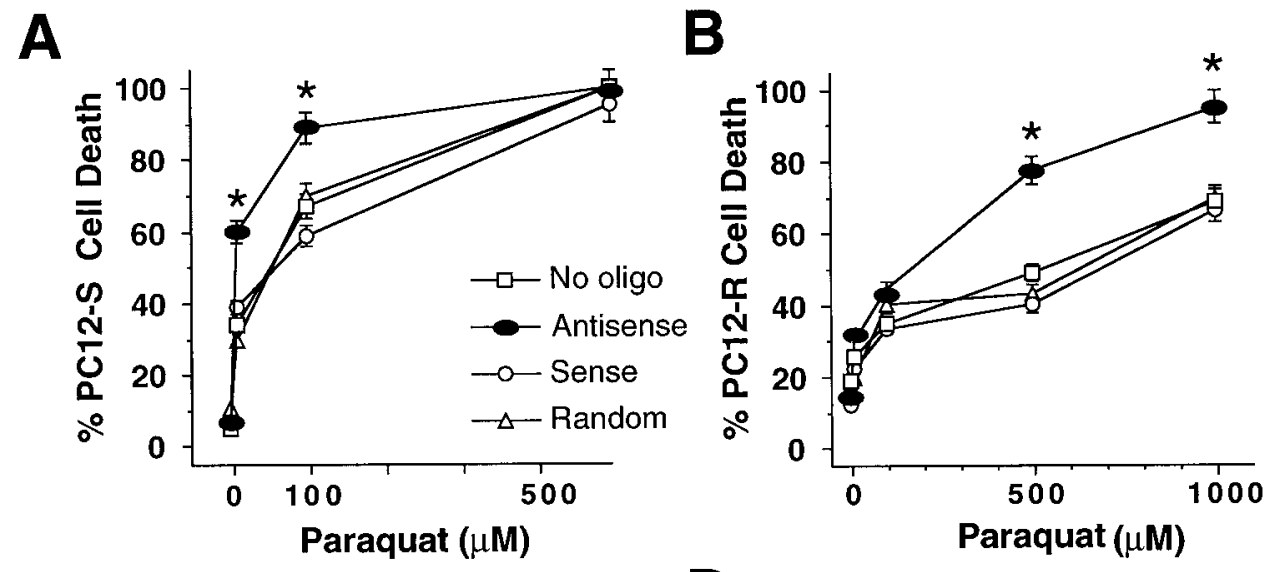

C

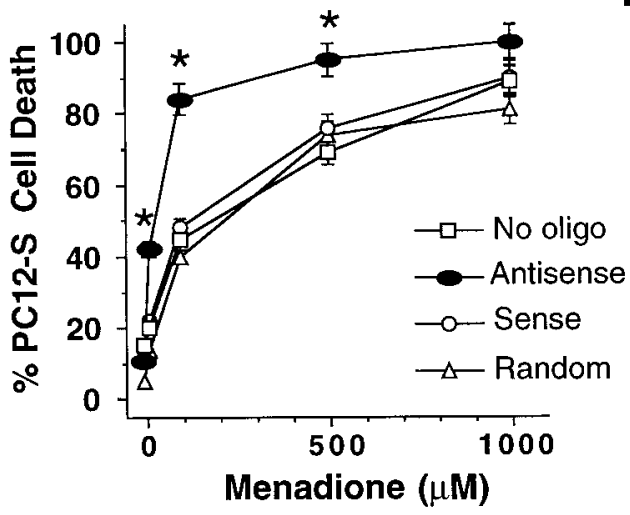

D

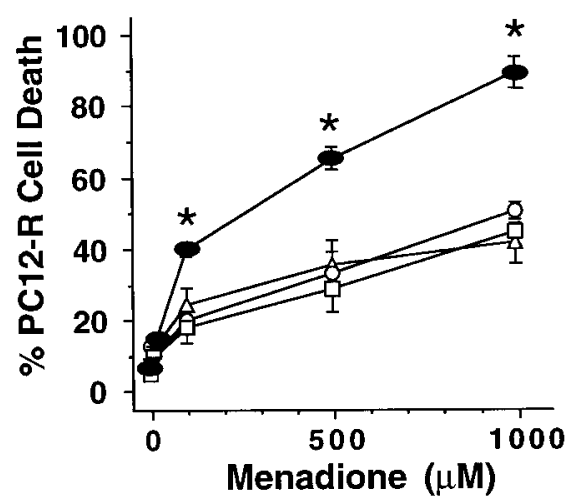

trast, $\mathrm{CuZnSOD}$ is expressed ubiquitously in all neurons with no enrichment in nNOS neurons (Fig. $6 J-L$ ). nNOS neurons represent $\sim 2 \%$ of the total neuronal population in cortical cultures, and immunohistochemical analysis of cortical neurons in culture indicates that every neuron that expresses nNOS also expresses MnSOD at high levels. We do not detect any nNOS-staining neuron that does not show intense positive staining for MnSOD. On the other hand, $2-5 \%$ of the total neuronal population in cortical cultures expresses high levels of MnSOD, and some of these neurons do not stain for nNOS. MnSOD-positive/nNOSnegative neurons show lower levels of MnSOD than MnSODpositive/nNOS-positive neurons (data not shown).

Treatment of cortical cultures with 300-500 $\mu \mathrm{M}$ NMDA enriches for nNOS neurons, whereas treatment with $20 \mu \mathrm{M}$ quisqualate depletes nNOS neurons from cortical cultures (V. L. Dawson et al., 1993). Using this approach we confirm the enrichment of nNOS neurons by NMDA treatment and the depletion of nNOS neurons after quisqualate treatment by Western blot analysis (Fig. 6M). Accompanying the enrichment in nNOS levels in NMDA-treated cultures is an enrichment in MnSOD (Fig. 6M). Quisqualate depletes both nNOS and MnSOD protein levels (Fig. $6 M$ ). NMDA and quisqualate treatments do not show any detectable effect on CuZnSOD levels or $\beta$-tubulin levels, thus confirming the specific enrichment of MnSOD in nNOS neurons.

\section{Antisense MnSOD renders nNOS neurons susceptible to NMDA toxicity}

Forty-eight hour exposure to $10 \mu \mathrm{M}$ antisense oligonucleotide to MnSOD effectively reduces MnSOD protein levels and catalytic activity in primary cortical neuronal cultures, as indicated by Western blot analysis and MnSOD catalytic activity (Fig. 7A). We then assessed the susceptibility of nNOS neurons and the total neuronal population to NMDA neurotoxicity after knockdown of MnSOD by antisense oligonucleotide (Fig. 7B,C). NMDA (300 $\mu \mathrm{M})$ kills $\sim 20-30 \%$ of the nNOS neurons. In the presence of 10 $\mu \mathrm{M}$ antisense oligonucleotide to MnSOD, $\sim 85 \%$ of the nNOS neurons die (Fig. $7 B$ ). After $500 \mu \mathrm{M}$ NMDA treatment, $\sim 50 \%$ of the nNOS neurons die, and exposure to antisense oligonucleotide to MnSOD leads to almost complete loss of nNOS neurons (Fig. $7 B$ ). In contrast, the increased susceptibility of the total neuronal population to either 300 or $500 \mu \mathrm{M}$ NMDA is not influenced by exposure to antisense oligonucleotide to MnSOD (Fig. $7 C$ ). Sense and random oligonucleotides with equivalent levels of sulfation do not have any detectable effect. Although phosphorothioate derivatives of oligos may be toxic, especially to neurons, we did not encounter any intrinsic neurotoxicity of our phosphorothioate derivatives. Indeed, our antisense, sense, and random oligos, which contain an equivalent amount of sulfation, have no intrinsic neurotoxicity in our neuronal cultures. Furthermore, the antisense MnSOD oligo only affected the susceptibility of nNOS neurons to NMDA neurotoxicity. To illustrate the differential resistance and susceptibility of nNOS neurons to NMDA neurotoxicity in the absence and presence of antisense oligonucleotide to MnSOD, respectively, we plotted the percentage of nNOS neuron survival versus the percentage of total neuronal survival (Fig. 7D). Consistent with the notion that nNOS neurons are markedly resistant to NMDA neurotoxicity is the observation that nNOS neurons preferentially survive NMDA treatment compared with the total neuronal population (Fig. $7 B-D$ ). In contrast, nNOS neurons are markedly susceptible to reductions in MnSOD, whereas the susceptibility of the total neuronal cell 
A

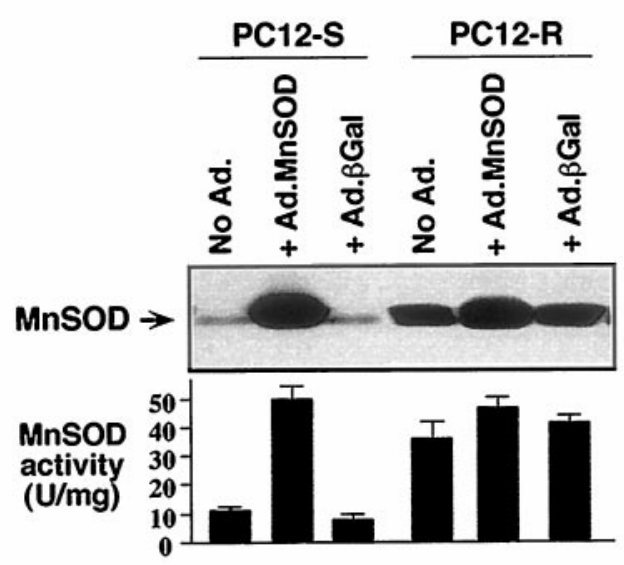

B
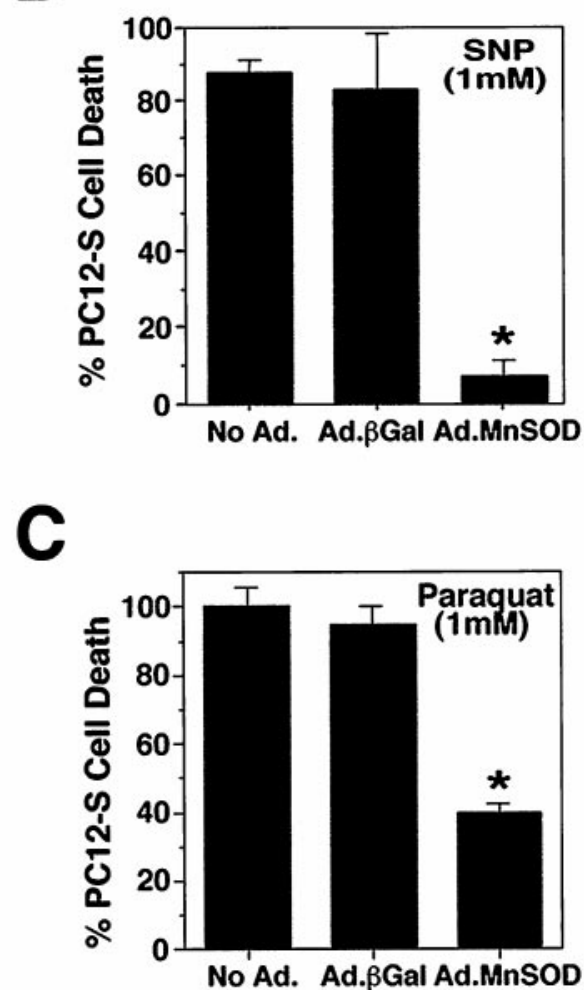

Figure 5. Overexpression of MnSOD confers resistance to NO toxicity in PC12 cells. $A$, Western blot and activity analyses demonstrate overexpression of MnSOD after infection of PC12-S and PC12-R cells with an adenovirus-derived vector containing the MnSOD gene. Cells were exposed to $10^{8}$ $\mathrm{pfu} / \mathrm{ml}$ of either an adenoviral vector containing the MnSOD gene (Ad.MnSOD) or a control adenoviral vector containing the $\beta$-galactosidase gene $(\mathrm{Ad} . \beta \mathrm{Gal}$ ). Cells were harvested $48 \mathrm{hr}$ after exposure to adenovirus for Western blot and activity analyses. Total protein (10 $\mu \mathrm{g})$ was loaded in each lane for Western blot analysis. Also at this time point, control cells infected with Ad. $\beta$ Gal were assayed for X-Gal staining to determine infection efficiency. The estimated infection efficiency was $90-100 \%$ with minimal cell loss. B, Effect of adenoviral-mediated overexpression of MnSOD on PC12-S susceptibility to SNP. Cells were exposed to $10^{8} \mathrm{pfu} / \mathrm{ml}$ of either Ad.MnSOD or Ad. $\beta \mathrm{Gal}$, and $24 \mathrm{hr}$ later they were treated with $1 \mathrm{~mm}$ SNP for $5 \mathrm{~min}$. Toxicity was assayed $24 \mathrm{hr}$ after treatment by trypan blue exclusion. $C$, Effect of adenoviral-mediated overexpression of MnSOD on PC12-S susceptibility to paraquat. Cells were exposed to $10^{8} \mathrm{pfu} / \mathrm{ml}$ of either Ad.MnSOD or Ad. $\beta \mathrm{Gal}$ and $24 \mathrm{hr}$ later were treated with $1 \mathrm{~mm}$ paraquat for 5 min. Toxicity was assayed $24 \mathrm{hr}$ after treatment by trypan blue exclusion. Data represents the mean \pm SEM of two to three independent experiments. Western blots are representative of two to three independent experiments. ${ }^{*} p<0.001$.

population to NMDA toxicity does not change after reductions in MnSOD.

\section{Overexpression of MnSOD confers resistance to NMDA and NO toxicity in primary cortical neurons}

A number of approaches have been used to transfect genes of interest into primary neurons (Werner et al., 1990). These approaches yield $\sim 1-2 \%$ transfection efficiency sometimes in the setting of marked toxicity. Various studies suggest that modified adenovirus is an efficient vector for successful gene transfer into neurons (Akli et al., 1993; Davidson et al., 1993; Le Gal La Salle et al., 1993). Despite the initial experiments indicating the feasibility of this approach, most investigators have not been able to achieve significant gene transfer efficiency in the setting of minimal neurotoxicity (Kozarsky and Wilson, 1993). The purification and storage of the virus are critical to the success of efficient infection of primary neurons with minimal toxicity. We now show 90-100\% infection efficiency in primary neuronal cultures, with essentially no loss of cell viability, as indicated by transfection of primary cortical cultures with Ad. $\beta$ Gal adenovirus (Fig. 8A). Although we routinely achieve $90-100 \%$ infection of neurons with adenovirus, there is some heterogeneity in the expression patterns. In a similar manner, we are able to infect $90-100 \%$ of cortical neurons with the Ad.MnSOD virus (Fig. $8 B-F$ ). Uninfected control cultures or cultures infected with Ad. $\beta \mathrm{Gal}$ show minimal immunostaining for MnSOD, with 2-5\% of the total neuronal population showing intense staining (data not shown). Cortical neurons transfected with Ad. $\beta$ Gal and Ad.MnSOD maintain a normal morphological appearance and remain viable, as demonstrated by a normal morphological appearance under Hoffman modulation optics and the absence of trypan blue staining (data not shown). Confirming that the Ad.MnSOD virus overexpresses MnSOD is our observation that MnSOD protein levels and catalytic activity are increased dramatically after infection with Ad.MnSOD, whereas Ad. $\beta$ Gal has no effect on MnSOD levels or catalytic activity (Fig. $9 A$ ).

Infection of primary cortical neurons with Ad.MnSOD confers resistance to NMDA toxicity at all doses examined, whereas Ad. $\beta$ Gal has no effect (Fig. 9B). We also compared the effects of adenoviral-mediated overexpression of MnSOD on kainate and AMPA toxicity with the effects on NMDA toxicity (Fig. 9C). Our results show that overexpression of MnSOD has no effect on kainate or AMPA toxicity but is protective against NMDA- 

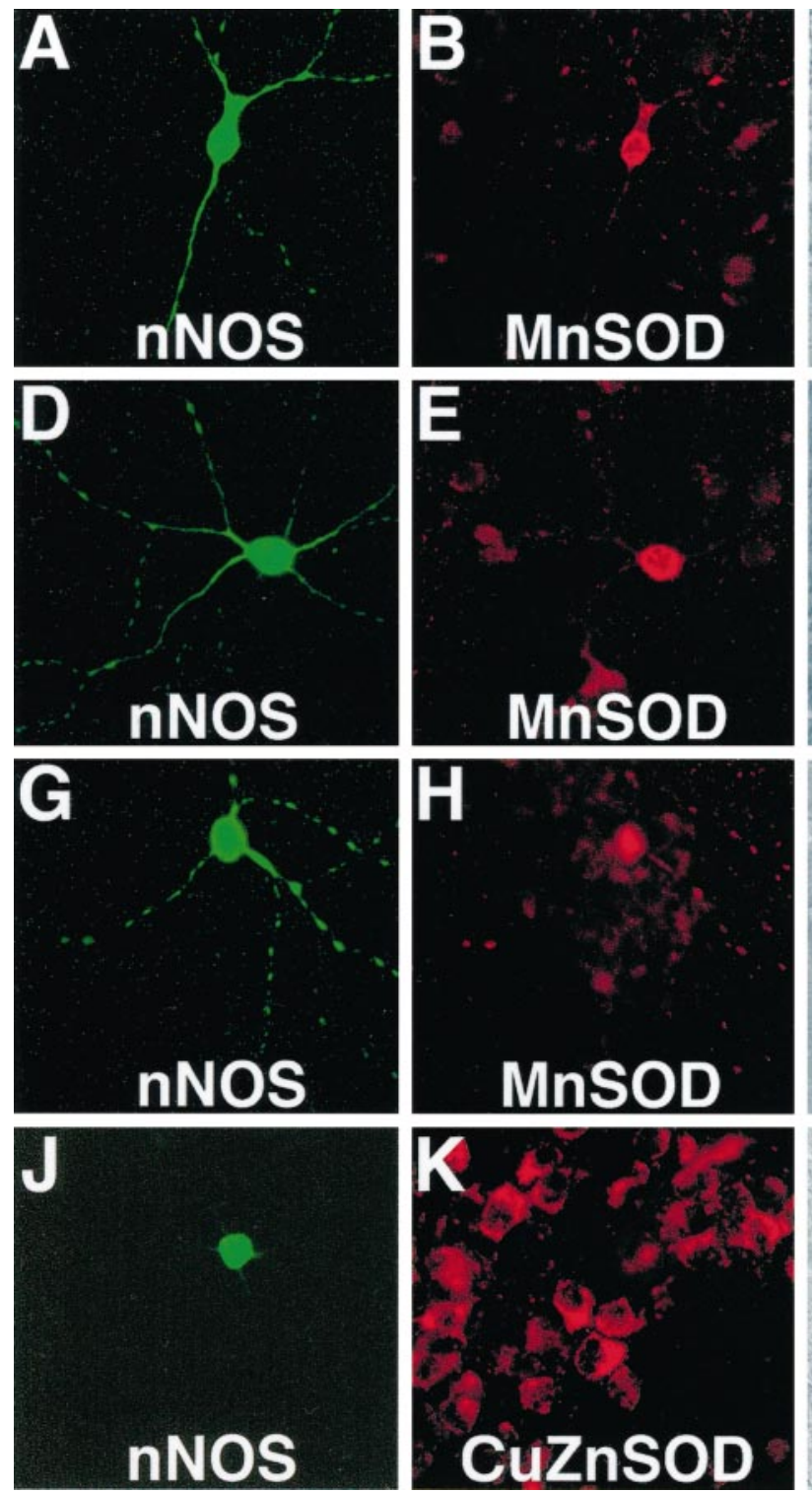
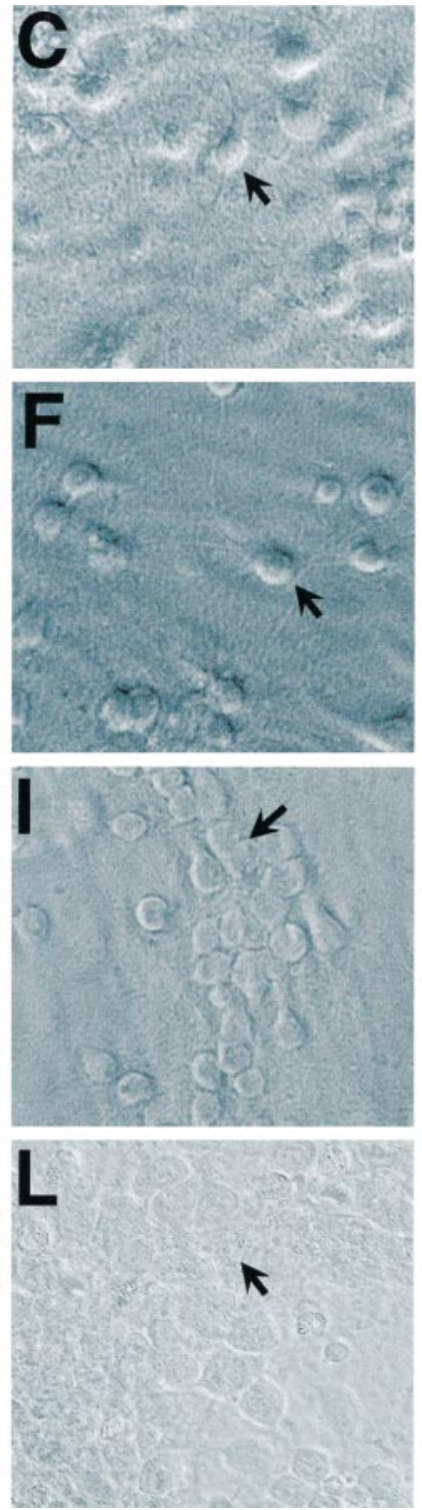

M

\section{$\mathrm{nNOS} \rightarrow=4$}

\section{MnSOD $\rightarrow$ G}

\section{CuZnSOD $\rightarrow$ MUE}

\section{B-Tubulin $\rightarrow=\mathbf{E}=$}

Figure 6. MnSOD is selectively enriched in nNOS neurons. Immunofluorescence staining of $14 \mathrm{~d}$ cultured rat cortical neurons indicates that nNOS neurons $(A, D, G)$ are enriched in $\operatorname{MnSOD}(B, E, H)$. nNOS and MnSOD are both extranuclear proteins concentrated mostly in the neuronal cell body and processes. In contrast, nNOS $(J)$ neurons are not enriched in CuZnSOD $(K)$, which is expressed ubiquitously in cortical neurons. Hoffman modulation images of cells are depicted to the right of the corresponding immunofluorescent images $(C, F, I, L)$, and arrows indicate nNOS neurons. $M$, MnSOD levels parallel nNOS levels after NMDA or quisqualate treatment. Western blot analysis of nNOS, MnSOD, CuZnSOD, and $\beta$-tubulin levels in primary cortical cultures after treatment with control salt solution $(C)$, NMDA $(N)$, or quisqualate $(Q)$. Rat neuronal cultures were exposed for 5 min to either $500 \mu \mathrm{M}$ NMDA or $20 \mu \mathrm{M}$ quisqualate. Twenty-four hours later, cells were harvested for Western blot analysis. Total protein (50 $\mu \mathrm{g})$ was loaded in each lane and electrophoresed in a denaturing $10 \%$ polyacrylamide gel. Immunofluorescent images and Western blots are representative of two to three independent experiments.

mediated neurotoxicity. This is consistent with the notion that NO neurotoxicity is mediated by NMDA receptor activation, but not by kainate or AMPA receptor activation (V. L. Dawson et al., 1993), and it further illustrates the selective protective effect of MnSOD on NMDA and NO-mediated toxicity. Adenoviralmediated overexpression of $\beta$-galactosidase has no effect on NMDA, kainate, or AMPA toxicity.

To assess the potential role of MnSOD in protecting cortical neurons from NO-mediated toxicity, we applied various NO donors and assessed neurotoxicity in primary cortical neuronal cultures after adenoviral-mediated overexpression of MnSOD (Fig. 9D). Overexpression of MnSOD provides dramatic protec- tion against SNP-, SIN-1-, and DETA/NO-mediated neurotoxicity, whereas overexpression of $\beta$-galactosidase has no detectable effect on NO toxicity (Fig. 9D).

\section{MnSOD is required for $\mathrm{nNOS}$ neuron resistance to NMDA-induced toxicity}

To test further whether MnSOD is the endogenous gene that confers resistance of nNOS neurons to NMDA-induced toxicity, we evaluated the susceptibility of nNOS neurons to NMDAinduced toxicity in mice in which the gene coding for MnSOD had been disrupted by homologous recombination (Li et al., 1995; Lebovitz et al., 1996). Sixty-one individual embryos from 


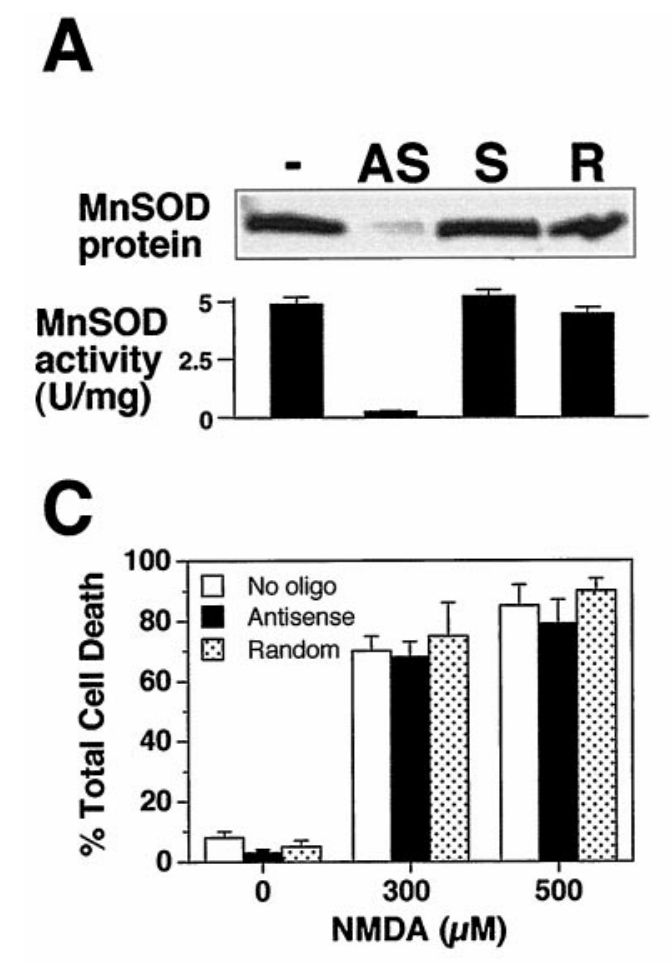

B

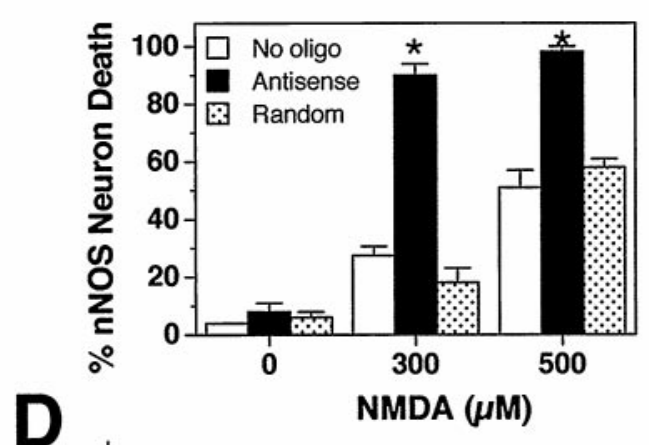

D

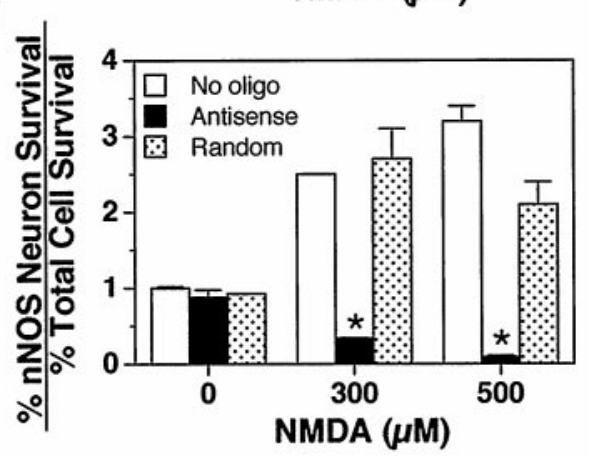

Figure 7. Antisense MnSOD renders nNOS neurons susceptible to NMDA toxicity. $A$, Western blot and activity analyses of MnSOD in primary cortical neurons after exposure to oligonucleotides. Cultures were exposed for $24 \mathrm{hr}$ to either no oligonucleotide $(-)$, antisense oligonucleotide to MnSOD ( $A S$ ), sense oligonucleotide $(S)$, or random oligonucleotide $(R)$. All oligonucleotides were used at $10 \mu \mathrm{M}$ concentration. Thirty micrograms of total protein were loaded in each lane. Catalytic activity data from three independent experiments were analyzed with the Student's $t$ test for independent means. Statistical analysis was performed by using StatView 4.0 software. MnSOD catalytic activity after antisense oligonucleotide knockdown was significantly different from MnSOD activity in untreated, sense, and random oligonucleotide-treated cells $(p<0.001)$. $B$, Effect of antisense knockdown of MnSOD on susceptibility of nNOS neurons to NMDA toxicity. Cultures were exposed to either no oligonucleotide, $10 \mu \mathrm{M}$ antisense oligonucleotide, or $10 \mu \mathrm{M}$ random oligonucleotide. Twenty-four hours later, cells were treated for 5 min with 0, 300, or $500 \mu \mathrm{M}$ NMDA, and fresh oligonucleotides were added to the medium. After $24 \mathrm{hr}$, cultures were stained for nNOS neurons by NADPH-diaphorase staining. $C$, Susceptibility of cultures to NMDA toxicity. Treatment was performed as in $A$, and total cell death was estimated by trypan blue staining $24 \mathrm{hr}$ after exposure to NMDA. $D$, The differential resistance and susceptibility of nNOS neurons to NMDA neurotoxicity in the absence and presence of antisense oligonucleotide to MnSOD, respectively, is illustrated by plotting the ratio between the percentage of nNOS neuron survival and the percentage of total neuronal survival. Data represents the mean \pm SEM of two to three independent experiments. Western blots are representative of two to three independent experiments. ${ }^{*} p<0.001$.

MnSOD heterozygous matings were screened for the MnSOD gene via Southern blot analysis and PCR. Ten $(16 \%)$ wild-type $(+/+), 34(56 \%)$ heterozygous $(+/-)$, and $17(28 \%)$ null $(-/-)$ independent cortical neuronal cultures were derived from each embryo and maintained in vitro in low $(5 \%) \mathrm{O}_{2}$ for $10 \mathrm{~d}$ before experiments were performed. Each culture was exposed to 100 $\mu \mathrm{M}$ NMDA for $5 \mathrm{~min}$. Twenty hours later, cell death and $\mathrm{NADPH}$-diaphorase staining for nNOS-containing neurons were assessed. The total neuronal population in $\mathrm{MnSOD}^{-/-}$cortical cultures is significantly more susceptible to the toxic effects of a relatively low dose $(100 \mu \mathrm{M})$ of NMDA, with a threefold increase in the proportion of total cell death (Fig. 10A). $\mathrm{MnSOD}^{+/-}$ cultures also tend to be more susceptible than wild-type cultures to NMDA-induced death. The nNOS neuronal population is significantly reduced in $\mathrm{MnSOD}^{+/-}$cultures and is almost completely lost in $\mathrm{MnSOD}^{-1-}$ mice after NMDA treatment (Fig. $10 B$ ). The dramatically increased susceptibility of nNOS neurons to NMDA toxicity in MnSOD-deficient cortical cultures is also evident when we calculate the ratio between the percentage of surviving nNOS neurons and the percentage of total cell survival (Fig. 10C). Estimation of this ratio is important in the analysis of our data because it demonstrates the dramatic effect of complete elimination of MnSOD on susceptibility to NMDA toxicity in
nNOS neurons, and that the sensitivity to NMDA-induced death is selectively increased in nNOS neurons.

\section{Adenoviral overexpression of MnSOD in $\mathrm{MnSOD}^{-/-}$ cultures rescues nNOS neurons from NMDA-induced death}

If the loss of nNOS neurons after NMDA treatment in cultures from MnSOD-deficient mice is caused by the lack of MnSOD, overexpression of the protein would be predicted to protect nNOS neurons from NMDA-induced death. Wild-type, $\mathrm{MnSOD}^{+/-}$, and $\mathrm{MnSOD}^{-/-}$cortical neuronal cultures from individual embryos were infected with Ad.MnSOD or Ad. $\beta \mathrm{Gal}$, and $48 \mathrm{hr}$ later they were treated with $100 \mu \mathrm{M}$ NMDA. Although no significant change in total cell death after NMDA treatment is observed in wild-type and $\mathrm{MnSOD}^{+/-}$cultures, overexpression of MnSOD significantly rescues $\mathrm{MnSOD}^{-1-}$ cultures from NMDA-induced death (Fig. 10D). Overexpression of MnSOD also has a dramatic protective effect on the nNOS neuronal population in $\mathrm{MnSOD}^{-1-}$ cultures, and to a lesser extent in the $\mathrm{MnSOD}^{+/-}$cultures (Fig. 10E). The proportion of surviving nNOS neurons after NMDA treatment in Ad.MnSOD-infected $\mathrm{MnSOD}^{-1-}$ cultures is comparable to that observed in wild-type 

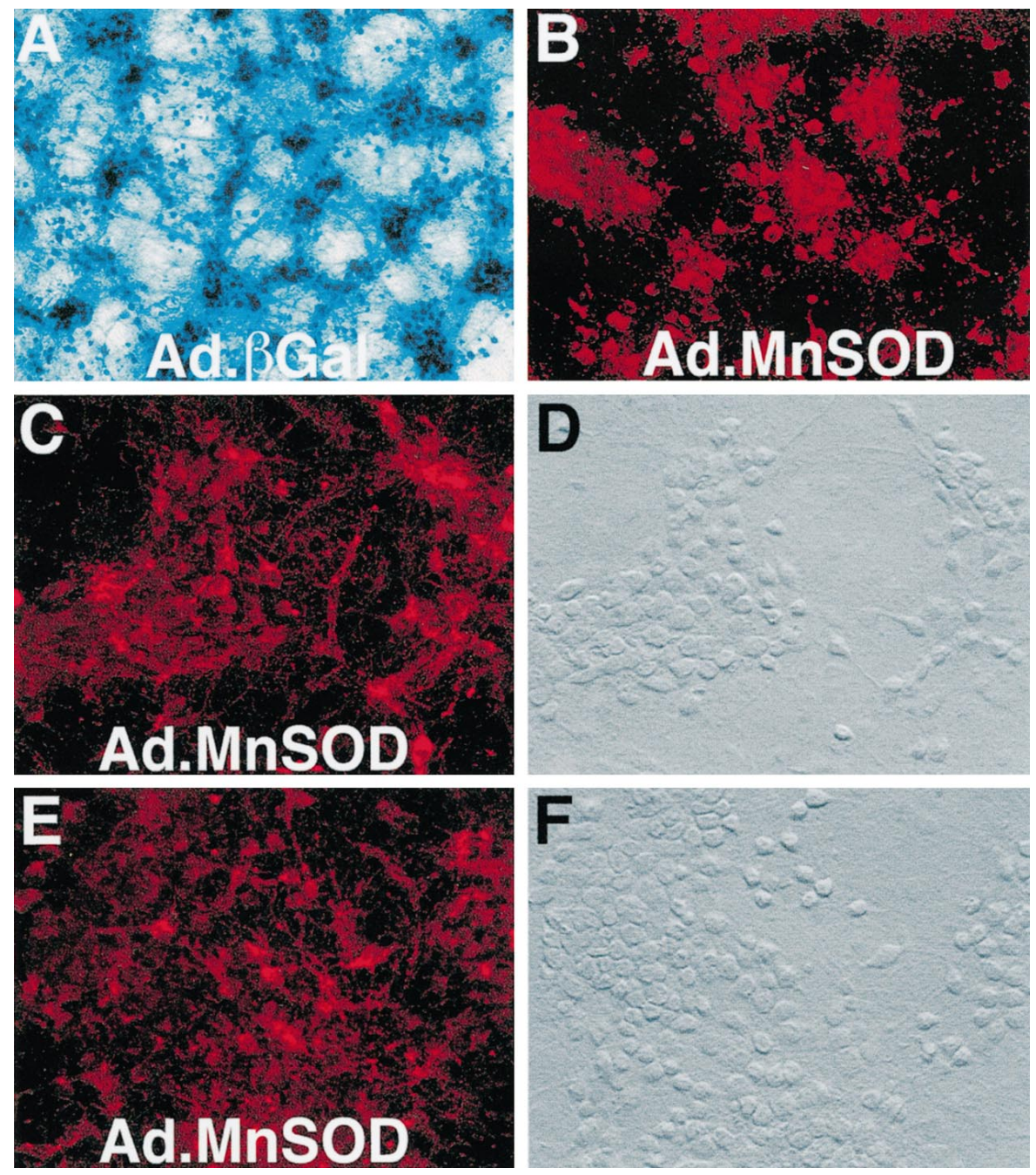

Figure 8. Efficient gene transfer into primary neurons using an adenovirus vector. $A$, Neurons $(90-100 \%)$ were infected with $10^{8} \mathrm{pfu} / \mathrm{ml}$ of an adenovirus containing the $\beta$-galactosidase reporter gene, as assessed by X-Gal staining $24 \mathrm{hr}$ after exposure of cultures to the virus. $B-F$, The rat MnSOD gene was efficiently transferred (90$100 \%$ infection efficiency) into primary neurons via an adenovirus ( $A d . M n S O D)$, as assessed by immunofluorescence staining of cultures $24 \mathrm{hr}$ after exposure to $10^{8} \mathrm{pfu} / \mathrm{ml}$ of Ad.MnSOD. $D, F$, Hoffman modulation images corresponding to panels $C$ and $E$, respectively. Images are representative of three to four independent experiments. cultures. The ratio of surviving nNOS neurons to total cell survival in the $\mathrm{MnSOD}^{-/-}$cultures after overexpression of MnSOD is also dramatically increased to wild-type levels (Fig. $10 F$ ). Thus, these data suggest that MnSOD is a major endogenous determinant of NMDA resistance in nNOS neurons.

\section{DISCUSSION}

The molecular mechanisms underlying the remarkable resistance of nNOS neurons to NMDA-glutamate receptor toxicity have been under intensive investigation. In this study, we provide several independent and complementary lines of evidence that MnSOD may be necessary for the selective resistance of nNOS neurons to NMDA neurotoxicity: (1) the NO-resistant PC12-R cell line contains elevated levels of MnSOD as determined by SAGE, Western blot, and catalytic activity analyses; (2) antisense oligonucleotide knockdown of MnSOD renders PC12-R cells susceptible to NO toxicity; (3) adenoviral overexpression of MnSOD confers resistance to NO toxicity in the NO-sensitive, PC12-S cell line; (4) nNOS neurons in rat cortical neuronal cultures are enriched in MnSOD; (5) antisense MnSOD causes nNOS neurons to become susceptible to NMDA toxicity, although it has little effect on overall neuronal toxicity; (6) adenovirus-mediated overexpression of MnSOD in cortical cultures confers resistance to NMDA and NO-mediated neurotoxicity but has no effect on kainate and AMPA neurotoxicity; (7)
nNOS neurons from $\mathrm{MnSOD}^{-/-}$mice are markedly susceptible to NMDA-induced toxicity; and finally, (8) nNOS neurons in $\mathrm{MnSOD}^{-/-}$mice are rescued from death by overexpressing MnSOD. Together these observations provide strong evidence that MnSOD may be the principal endogenous protective protein against NMDA and NO-mediated neurotoxicity in nNOS neurons.

\section{MnSOD is critical for survival against NO toxicity}

The majority of NO induced toxicity may occur through an interaction with $\mathrm{O}_{2}{ }^{\bullet-}$ to form the highly reactive and toxic free radical peroxynitrite (Radi et al., 1991; Beckman and Crow, 1993; Beckman, 1994; Xia et al., 1996). Thus, excess production of either $\mathrm{NO}$ or $\mathrm{O}_{2}{ }^{\bullet-}$ could lead to deleterious generation of peroxynitrite. Peroxynitrite may inactivate MnSOD through tyrosine nitration and contribute to further cytotoxicity by diminishing mitochondrial $\mathrm{O}_{2}{ }^{\bullet-}$ scavenger capacity (MacMillan-Crow et al., 1996). Thus, it may be critical to prevent mitochondrial peroxynitrite formation by effective scavenging of $\mathrm{O}_{2}{ }^{\bullet-}$. Although $\mathrm{Mn}-$ SOD is important in the cellular defense against excess $\mathrm{O}_{2}{ }^{\bullet-}$, it appears to play a more significant role against NO toxicity. Consistent with this notion are our observations that alterations in MnSOD levels have more pronounced effects on NO toxicity than on $\mathrm{O}_{2}{ }^{\bullet-}$ toxicity. Mammalian cells have several enzymes that scavenge $\mathrm{O}_{2}{ }^{\bullet-}$, including the cytosolic CuZnSOD and the 


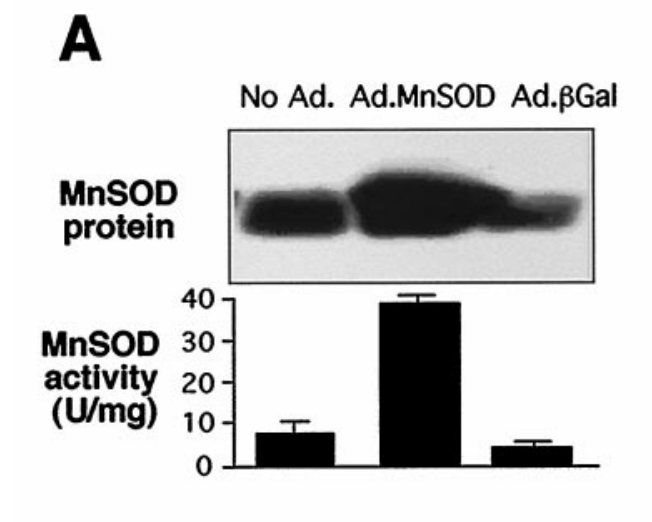

B
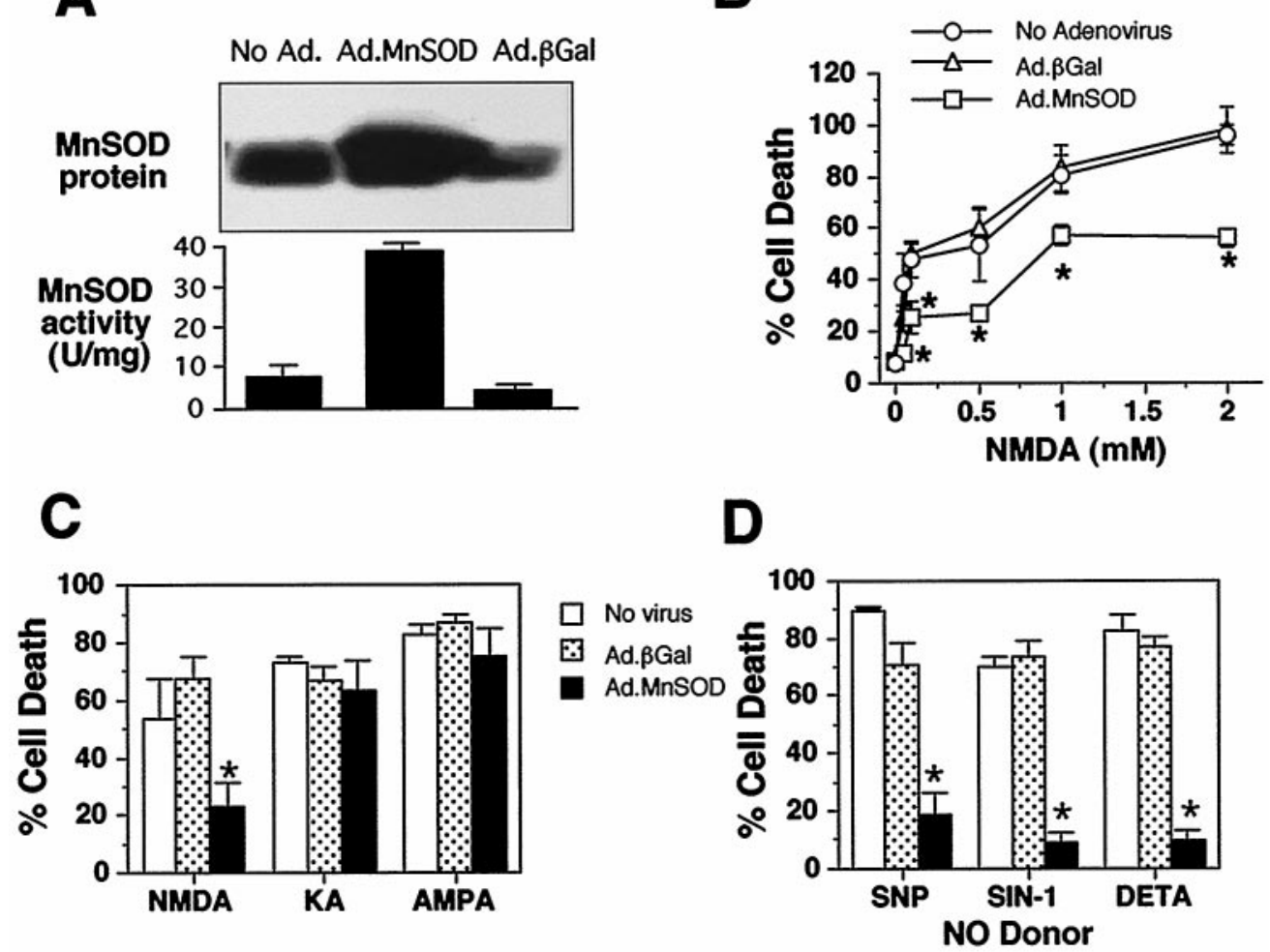

Figure 9. MnSOD overexpression confers resistance to NMDA and NO toxicity in primary cortical neurons. $A$, Western blot and activity analyses of MnSOD in rat cortical neurons after in vitro exposure to either control salt solution (No $A d$.), $10^{8}$ pfu/ml of MnSOD-containing adenovirus (Ad.MnSOD), or $10^{8} \mathrm{pfu} / \mathrm{ml}$ of $\beta$-galactosidase-containing adenovirus (Ad. $\beta \mathrm{Gal}$ ). Cells were harvested for Western blot and activity analyses 48 hr after exposure to the adenovirus. $B$, Susceptibility of cortical neurons to NMDA toxicity in cultures that were not exposed to adenovirus and in cultures infected with Ad.MnSOD or Ad. $\beta$ Gal. $C$, Susceptibility of cortical neurons to $N M D A$, kainate $(K A)$, and $A M P A$ after exposure to control salt solution (no virus), Ad.MnSOD, or Ad. $\beta$ Gal. Cultures were exposed to $10^{8} \mathrm{pfu} / \mathrm{ml}$ Ad.MnSOD or Ad. $\beta \mathrm{Gal}$, and $24 \mathrm{hr}$ later treated with $0.5 \mathrm{~mm}$ NMDA, $0.1 \mathrm{~mm}$ kainate, or $0.1 \mathrm{~mm}$ AMPA. NMDA was applied for $5 \mathrm{~min}$ and then washed off. KA and AMPA were applied for $14 \mathrm{hr}$. Toxicity was assessed $24 \mathrm{hr}$ after exposure to the toxic agent by trypan blue exclusion. $D$, Susceptibility of cortical neurons to NO donors after exposure to control salt solution (no virus), Ad.MnSOD, or Ad. $\beta$ Gal. Cultures were exposed to $10^{8} \mathrm{pfu} / \mathrm{ml}$ Ad.MnSOD, or Ad. $\beta$ Gal, and 24 hr later they were treated for 5 min with 1 mM SNP, $2 \mathrm{~mm}$ SIN-1, or $2 \mathrm{~mm}$ DETA/NO. Toxicity was assessed $24 \mathrm{hr}$ after exposure to the toxic agent by trypan blue exclusion. Data represents the mean \pm SEM of two to three independent experiments. Western blots are representative of two to three independent experiments. ${ }^{*} p<0.001$.

mitochondrial MnSOD (McCord, 1969; Fridovich, 1986; Bannister et al., 1987; Hassan, 1988; Fridovich, 1995). Previous studies suggest that CuZnSOD may play an important role in $\mathrm{NO} /$ peroxynitrite-mediated cell death (Troy et al., 1996). However, our observations that (1) CuZnSOD levels remain unchanged in the PC12-R NO-resistant cell line, (2) CuZnSOD is ubiquitously expressed in cultured cortical neurons, and (3) CuZnSOD levels are not altered by NMDA or quisqualate treatments that enrich and deplete cultures of nNOS neurons, respectively, indicate that under normal conditions CuZnSOD probably plays a minimally protective role against NMDA and NO neurotoxicity in nNOS neurons. On the other hand, MnSOD, which is enriched in nNOS neurons and NO-resistant PC12-R cells, seems to play a major role in protection against NMDA and NO toxicity. The importance of mitochondrial scavenging of $\mathrm{O}_{2}{ }^{\bullet-}$ is further illustrated by the recent demonstration that only overexpression of MnSOD, but not $\mathrm{CuZnSOD}$ or mutant MnSOD lacking the mitochondrial matrix signal, protects against free radical toxicity (Wong, 1995). Furthermore, insertion of the mitochondrial signal sequence into CuZnSOD results in protection against free radical attack (Wong, 1995).

\section{MnSOD is essential and sufficient for $\mathrm{nNOS}$ neuron resistance to NMDA toxicity}

Since the original description of NADPH-diaphorase neurons surviving stroke damage by Thomas and Pearse (1964), and the remarkable survival of NADPH-diaphorase neurons in the setting of severe neuronal loss in the striatum of Huntington's disease (Ferrante et al., 1985), the molecular mechanisms underlying the resistance of nNOS neurons to these insults as well as NMDA neurotoxicity have been a mystery. The discovery that nNOS catalytic activity accounts for NADPH-diaphorase staining provided clues but no obvious explanation (T. M. Dawson et al., 1991; Hope et al., 1991). Various theories on the remarkable resistance of nNOS neurons to toxic insults have ranged from the expression of nNOS as the responsible mechanism, the expression of unknown protective proteins, to the relative lack of glutamate receptor expression (Dawson et al., 1992). Recent colocalization studies of nNOS with glutamate receptor subunits suggest that nNOS neurons do contain glutamate receptors (Catania et al., 1995; Landwehrmeyer et al., 1995; Standaert et al., 1996). Experiments in $\mathrm{nNOS}^{-1-}$ mice indicate that nNOS itself does not account for the selective resistance of nNOS neurons to NMDA 
A

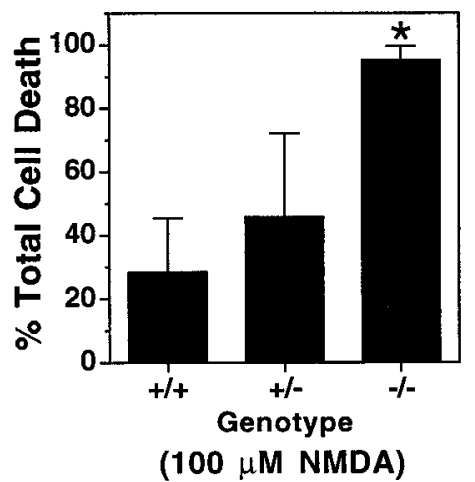

D

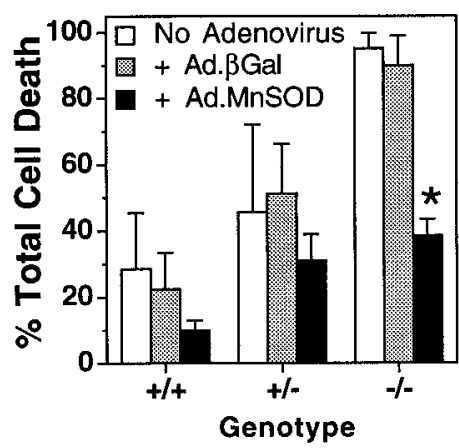

(100 $\mu$ M NMDA)
B
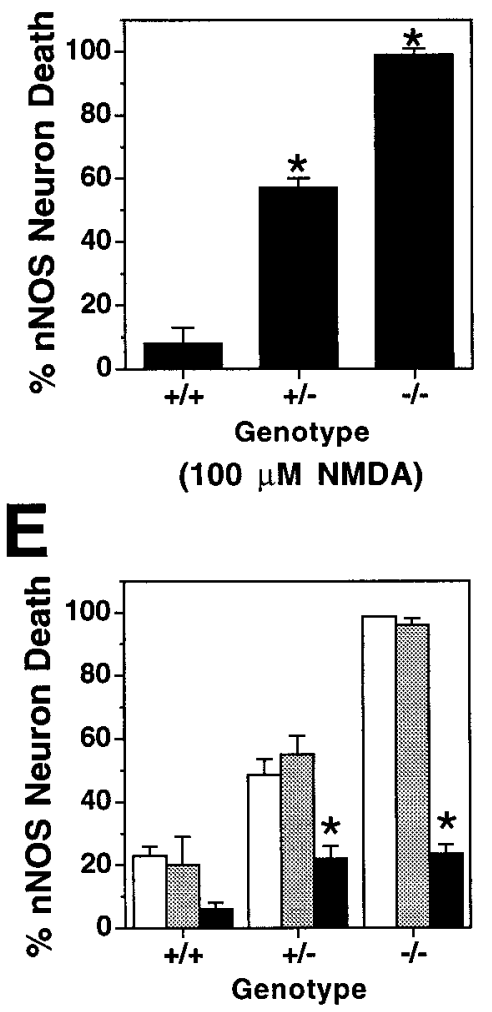

(100 $\mu$ M NMDA)
C

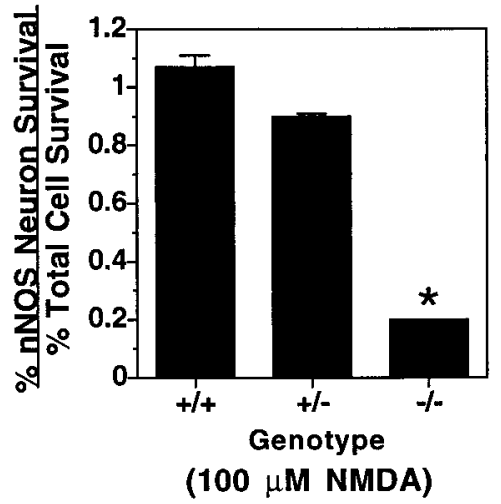

$\mathbf{F}$

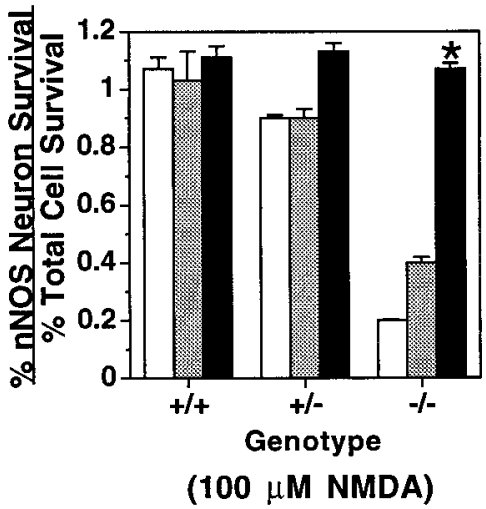

Figure 10. MnSOD is required for nNOS neuron survival. $A$, Effect of targeted disruption of MnSOD on susceptibility of cortical neurons to NMDA toxicity. Wild-type $(+/+), \mathrm{MnSOD}^{+/-}$, and $\mathrm{MnSOD}^{-/-}$cultures were treated for 5 min with $100 \mu \mathrm{M}$ NMDA, and total cell death was estimated by trypan blue staining or computer-assisted cell counting $24 \mathrm{hr}$ after exposure to NMDA. $B$, Effect of targeted disruption of MnSOD on susceptibility of nNOS neurons to NMDA toxicity. Cultures were treated for 5 min with $100 \mu \mathrm{M}$ NMDA, and after 24 hr cells were stained for nNOS neurons by NADPH-diaphorase staining. $C$, The differential resistance and susceptibility of nNOS neurons to NMDA neurotoxicity in wildtype (+/+), $\mathrm{MnSOD}^{+/-}$, and $\mathrm{MnSOD}^{-/-}$cultures is illustrated by plotting the ratio between the percentage of nNOS neuronal survival and the percentage of total neuronal survival. $D$, Susceptibility of cortical neurons to $100 \mu \mathrm{M}$ NMDA toxicity in wild-type $(+/+), \mathrm{MnSOD}^{+/-}$, and $\mathrm{MnSOD}^{-/-}$cultures that were not exposed to adenovirus and in cultures infected with Ad.MnSOD or Ad. $\beta$ Gal. $E$, Susceptibility of nNOS neurons to $100 \mu \mathrm{M}$ NMDA toxicity in wild-type $(+/+), \mathrm{MnSOD}^{+/-}$, and $\mathrm{MnSOD}^{-1-}$ cultures that were not exposed to adenovirus and in cultures infected with Ad.MnSOD or Ad. $\beta$ Gal. $F$, The differential resistance and susceptibility of nNOS neurons to NMDA neurotoxicity in wild-type $(+/+), \mathrm{MnSOD}^{+/-}$, and $\mathrm{MnSOD}^{-/-}$cultures that were not exposed to adenovirus and in cultures infected with Ad.MnSOD or Ad. $\beta$ Gal is illustrated by plotting the ratio between the percentage of nNOS neuronal survival and the percentage of total neuronal survival. Data represent the mean \pm SEM of five independent experiments. ${ }^{*} p<0.001$.

neurotoxicity (Dawson et al., 1996). However, nNOS ${ }^{-1-}$ mice were later shown to express enzymatically active splice variants of nNOS (Brenman et al., 1996). Although these splice variants fail to produce NO upon NMDA receptor stimulation (Dawson et al., 1996), it is still possible that nNOS activity may account, at least in part, for the selective resistance of nNOS neurons to damage.

It is quite surprising that MnSOD is selectively enriched in cultured cortical nNOS neurons and that it plays a critical role in the selective resistance of nNOS neurons to NMDA-induced neurotoxicity. We would have expected an enzyme such as MnSOD to be expressed ubiquitously and to play a major protective role against most, if not all, toxic insults. However, MnSOD is dramatically enriched in cultured nNOS neurons, because no nNOS neuron was detected that did not show intense positive staining for MnSOD. On the other hand, some neurons expressed relatively high levels of MnSOD and did not stain for nNOS. Detailed and comprehensive immunohistochemical studies in rodent brain on the localization of MnSOD have not been reported. However, limited studies indicate that MnSOD has a heterogeneous distribution. In the striatum, MnSOD is enriched in cholinergic neurons and somatostatin neurons, which contain nNOS (Inagaki et al., 1991a). It is also highly enriched in cholinergic neurons of the basal forebrain (Inagaki et al., 1991b). In the hippocampus, MnSOD is enriched mainly in parvalbumincontaining neurons and is rarely in nNOS neurons (Matsui et al., 1996). Thus, in some regions of the brain the selective resistance of nNOS neurons may be attributed to other factors. Future studies will be required to determine the amount of coexpression of nNOS and MnSOD in rodent brain.

Our findings that MnSOD is required for nNOS neuron survival after NMDA-induced toxicity in cultures from MnSODdeficient mice are critical in supporting and complementing the data obtained in PC12 cells and rat cortical cultures after antisense oligonucleotide knockdown of MnSOD mRNA and adenovirus-mediated overexpression of MnSOD. Previous studies that have suggested that MnSOD is important for the resistance to toxic cellular insults have relied on overexpression or antisense knockdown of MnSOD (Jones, 1986; Wong et al., 1989; 
Wong, 1995). These methods do not insure that MnSOD is the endogenous mechanism of protection. Our findings in $\mathrm{MnSOD}^{-1-}$ mice provide a direct demonstration that endogenous MnSOD is essential and sufficient for the cellular survival against toxic insults. The complete absence of MnSOD renders nNOS neurons dramatically sensitive to the toxic effects of NMDA, and adenoviral replacement of MnSOD preferentially enhances the survival of nNOS neurons to NMDA-induced toxicity. Thus, MnSOD plays a key protective role against NMDAinduced toxicity in neurons containing nNOS.

\section{Glutamate neurotoxicity and mitochondrial function}

Recent studies indicate that mitochondrial dysfunction is a primary event in glutamate neurotoxicity (Schinder et al., 1996; White and Reynolds, 1996). A perfect balance between mitochondrial function and intracellular calcium homeostasis is essential for cell survival. Overstimulation of NMDA receptors causes a massive $\mathrm{Ca}^{2+}$ influx that leads to an imbalance in mitochondrial homeostasis and mitochondrial dysfunction that in turn triggers subsequent neuronal death cascades (Schinder et al., 1996; White and Reynolds, 1996). Given the high metabolic requirements of the brain, it is reasonable to hypothesize that mitochondria are principal targets of calcium-dependent effectors of excitotoxicity (White and Reynolds, 1996). The mitochondrial electron transport chain is sensitive to NO and free radical generation (Zhang et al., 1990; Schweizer and Richter, 1994). Recent evidence suggests that oxidizing agents increase the likelihood of activation of the permeability transition pore in the mitochondrial membrane, which results in mitochondrial depolarization (Connern and Halestrap, 1994). Mitochondrial depolarization and alteration of the electron transport chain decrease ATP synthesis. The reduction of cellular energy together with the generation of oxygen free radicals subsequent to excitotoxic stimulation and high ATP consumption lead to cell collapse. Furthermore, the mitochondrial electron transport chain has been shown to be an important source of glutamate-induced reactive oxygen species (Dugan et al., 1995). Thus, free radical formation as indicated by oxidation of nonfluorescent dihydrorhodamine 123 to fluorescent rhodamine 123 is dramatically and specifically enhanced by NMDA receptor activation but not by kainate receptor activation (Dugan et al., 1995). Our observation that MnSOD protects cortical cultures against NMDA-mediated neurotoxicity, but not against AMPA or kainate toxicity, further substantiates the importance of mitochondrial dysfunction in NMDA neurotoxicity as well as the selective protective effects of MnSOD against NMDA and NO-mediated toxicity. Because the rate of reaction of $\mathrm{NO}$ with $\mathrm{O}_{2}{ }^{\bullet-}$ to form peroxynitrite is extremely rapid, peroxynitrite production is particularly limited by the diffusion constants of $\mathrm{NO}$ and $\mathrm{O}_{2}{ }^{\bullet-}$. Because mitochondria are an important source of free radical formation after NMDA neurotoxicity, the selective enrichment of MnSOD in nNOS neurons effectively scavenges excess $\mathrm{O}_{2}{ }^{\bullet-}$ and protects nNOS neurons against the toxic effects of NO. On the other hand, NO diffuses to adjacent non-nNOS neurons and reacts with NMDAinduced $\mathrm{O}_{2}{ }^{\bullet-}$, which is not effectively scavenged in mitochondria. Thus, peroxynitrite is preferentially produced in non-nNOS neurons, ultimately setting in motion irreversible processes leading to cell death.

Although MnSOD seems to be a major protective protein that confers resistance to nNOS neurons to NMDA and NO mediated-neurotoxicity, we cannot exclude the possibility that other protective proteins exist and are preferentially expressed in
nNOS neurons. Consistent with this notion is our observation that almost complete elimination of MnSOD catalytic activity in the PC12-R NO-resistant cell line does not lead to complete susceptibility to NO-mediated toxicity. Furthermore, by using differential display analysis of NMDA-treated cortical cultures versus quisqualate-treated cortical cultures, we have identified novel transcripts that are enriched in nNOS neurons (V. Christov, V. L. Dawson, and T. M. Dawson, unpublished observations). Thus, nNOS neurons may preferentially express multiple protective genes, within which MnSOD plays a major protective role.

\section{REFERENCES}

Akli S, Caillaud C, Vigne E, Stratford-Pericaudet LD, Poenaru L, Perricaudet M, Kahn A (1993) Transfer of a foreign gene into the brain using adenovirus vectors. Nat Genet 3:224-228.

Bannister JA, Bannister WH, Rotilio G (1987) Aspects of the structure, function, and applications of superoxide dismutase. Crit Rev Biochem 22:111-180.

Beal MF, Kowall NW, Ellison DW (1986) Replication of the neurochemical characteristics of Huntington's disease by quinolinic acid. Nature 321:168-171.

Beckman JS (1994) Peroxynitrite versus hydroxyl radical: the role of nitric oxide in superoxide-dependent cerebral injury. Ann NY Acad Sci 738:69-75.

Beckman JS, Crow JP (1993) Pathological implications of nitric oxide, superoxide and peroxynitrite formation. Biochem Soc Trans 21:330-334.

Beckman JS, Beckman TW, Chen J, Marshall PA, Freeman BA (1990) Apparent hydroxyl radical production by peroxynitrite: implications for endothelial injury from nitric oxide and superoxide. Proc Natl Acad Sci USA 87:1620-1624.

Bito H, Deisseroth K, Tsien RW (1996) CREB phosphorylation and dephosphorylation: a $\mathrm{Ca}(2+)$ - and stimulus duration-dependent switch for hippocampal gene expression. Cell 87:1203-1214.

Bredt DS, Snyder SH (1994) Nitric oxide: a physiologic messenger molecule. Annu Rev Biochem 63:175-195.

Bredt DS, Glatt CE, Hwang PM, Fotuhi M, Dawson TM, Snyder SH (1991) Nitric oxide synthase protein and mRNA are discretely localized in neuronal populations of the mammalian CNS together with NADPH diaphorase. Neuron 7:615-624.

Brenman JE, Chao DS, Gee SH, McGee AW, Craven SE, Santillano DR, Wu Z, Huang F, Xia H, Peters MF, Froehner SC, Bredt DS (1996) Interaction of nitric oxide synthase with the postsynaptic density protein PSD-95 and alpha1-syntrophin mediated by PDZ domains. Cell 84:757-767.

Catania MV, Tolle TR, Monyer H (1995) Differential expression of AMPA receptor subunits in NOS-positive neurons of cortex, striatum, and hippocampus. J Neurosci 15:7046-7061.

Choi DW (1988) Glutamate neurotoxicity and diseases of the nervous system. Neuron 1:623-634.

Choi DW, Rothman SM (1990) The role of glutamate neurotoxicity in hypoxic-ischemic neuronal death. Annu Rev Neurosci 13:171-182.

Connern CP, Halestrap AP (1994) Recruitment of mitochondrial cyclophilin to the mitochondrial inner membrane under conditions of oxidative stress that enhance the opening of a calcium-sensitive nonspecific channel. Biochem J 302:321-324.

Dalkara T, Moskowitz MA (1994) The complex role of nitric oxide in the pathophysiology of focal cerebral ischemia. Brain Pathol 4:49-57.

Davidson BL, Allen DE, Kozarsky KF, Wilson JM, Roessler BJ (1993) A model system for in vivo gene transfer into the central nervous system using an adenoviral vector. Nat Genet 3:219-223.

Dawson TM, Snyder SH (1994) Gases as biological messengers: nitric oxide and carbon monoxide in the brain. J Neurosci 14:5147-5159.

Dawson TM, Bredt DS, Fotuhi M, Hwang PM, Snyder SH (1991) Nitric oxide synthase and neuronal NADPH diaphorase are identical in brain and periphral tissues. Proc Natl Acad Sci USA 88:7797-7801.

Dawson TM, Dawson VL, Snyder SH (1992) A novel neuronal messenger in the brain: the free radical, nitric oxide. Ann Neurol 32:297-311.

Dawson TM, Steiner JP, Dawson VL, Dinerman JL, Uhl GR, Snyder SH (1993) Immunosuppressant F K506 enhances phosphorylation of nitric oxide synthase and protects against glutamate neurotoxicity. Proc Natl Acad Sci USA 90:9808-9812. 
Dawson VL, Dawson TM (1996) Free radicals and neuronal cell death. Cell Death Differ 3:71-78.

Dawson VL, Dawson TM, London ED, Bredt DS, Snyder SH (1991) Nitric oxide mediates glutamate neurotoxicity in primary cortical cultures. Proc Natl Acad Sci USA 88:6368-6371.

Dawson VL, Dawson TM, Bartley DA, Uhl GR, Snyder SH (1993) Mechanisms of nitric oxide-mediated neurotoxicity in primary brain cultures. J Neurosci 13:2651-2661.

Dawson VL, Kizushi VK, Huang PL, Snyder SH, Dawson TM (1996) Resistance to neurotoxicity in cortical neuronal cultures from neuronal nitric oxide synthase deficient mice. J Neurosci 16:2479-2487.

Dugan LL, Sensi SL, Canzoniero LMT, Handran SD, Rothman SM, Lin T-S, Goldberg MP, Choi DW (1995) Mitochondrial production of reactive oxygen species in cortical neurons following exposure to $N$-methyl-D-aspartate. J Neurosci 15:6377-6388.

Eliasson MJL, Sampei D, Mandir AS, Hurn PD, Traystman RJ, Bao J, Pieper A, Wang Z-Q, Dawson TM, Snyder SH, Dawson VL (1997) Poly (ADP-ribose) polymerase gene disruption renders mice resistant to cerebral ischemia. Nat Med 3:1089-1095.

Ferrante RJ, Kowall NW, Beal MF, Richardson EP, Bird ED, Martin JB (1985) Selective sparing of a class of striatal neurons in Huntington's disease. Science 230:561-563.

Fridovich I (1986) Superoxide dismutases. Adv Enzymol Relat Areas Mol Biol 58:61-97.

Fridovich I (1995) Superoxide radical and superoxide dismutases. Annu Rev Biochem 64:97-112.

Garthwaite J, Boulton CL (1995) Nitric oxide signaling in the central nervous system. Annu Rev Physiol 57:683-706.

Hassan HM (1988) Biosynthesis and regulation of superoxide dismutases. Free Radical Biol Med 5:377-385.

Hope BT, Michael GJ, Knigge KM, Vincent SR (1991) Neuronal NADPH diaphorase is a nitric oxide synthase. Proc Natl Acad Sci USA 88:2811-2814.

Huang PL, Dawson TM, Bredt DS, Snyder SH, Fishman MC (1993) Targeted disruption of the neuronal nitric oxide synthase gene. Cell 75:1273-1286.

Huang Z, Huang PL, Panahian N, Dalkara T, Fishman MC, Moskowitz MA (1994) Effects of cerebral ischemia in mice deficient in neuronal nitric oxide synthase. Science 265:1883-1885.

Hyman BT, Marzloff K, Wenniger JJ, Dawson TM, Bredt DS, Snyder SH (1992) Relative sparing of nitric oxide-containing neurons in the hippocampal formation in Alzheimer disease. Ann Neurol 32:818-824.

Iadecola C (1997) Bright and dark sides of nitric oxide in ischemic brain injury. Trends Neurosci 20:132-139.

Inagaki S, Suzuki K, Taniguchi N, Takagi H (1991a) Localization of Mn-superoxide dismutase (Mn-SOD) in cholinergic and somatostatincontaining neurons in the rat neostriatum. Brain Res 549:174-177.

Inagaki S, Takagi H, Suzuki K, Akai F, Taniguchi N (1991b) Intense immunoreactivity for Mn-superoxide dismutase (Mn-SOD) in cholinergic and non-cholinergic neurons in the rat basal forebrain. Brain Res 541:354-357.

Jones GRN (1986) Free radicals and immunological killing: the case of tumor necrosis factor. Med Hypotheses 21:267-271.

Koh J-Y, Peters S, Choi DW (1986) Neurons containing NADPHdiaphorase are selectively resistant to quinolinate toxicity. Science 234:73-76.

Koh J-Y, Choi DW (1988) Vulneability of cultures cortical neurons to damage by excitotoxins: differential susceptibility of neurons containing NADPH-diaphorase. J Neurosci 8:2153-2163.

Kozarsky KF, Wilson JM (1993) Gene therapy: adenovirus vectors. Curr Opin Genet Dev 3:499-503.

Landwehrmeyer GB, Standaert DG, Testa CM, Penney JB, Young AB (1995) NMDA receptor subunit mRNA expression by projection neurons and interneurons in rat striatum. J Neurosci 15:5297-5307.

Lautier D, Lagueux J, Thibodeau J, Menard L, Poirier GG (1993) Molecular and biochemical features of poly(ADP-ribose) metabolism. Mol Cell Biochem 122:171-193.

Lebovitz RM, Zhang H, Vogel H, Cartwright J, Dionne L, Lu N, Huang S, Matzuk MM (1996) Neurodegeneration, myocardial injury, and perinatal death in mitochondrial superoxide dismutase-deficient mice. Proc Natl Acad Sci USA 93:9782-9787.

Le Gal La Salle G, Robert JJ, Berrard S, Ridoux V, Stratford-Perricaudet LD, Perricaudet M, Mallet J (1993) An adenovirus vector for gene transfer into neurons and glia in the brain. Science 259:988-990.

Li Y, Huang TT, Carlson EJ, Melov S, Ursell PC, Olson JL, Noble LJ,
Yoshimura MP, Berger C, Chan PH, Wallace DC, Epstein CJ (1995) Dilated cardiomyopathy and neonatal lethality in mutant mice lacking manganese superoxide dismutase. Nat Med 11:376-381.

Lipton SA, Rosenberg PA (1994) Excitatory aminoacids as a final common pathway for neurologic disorders. N Engl J Med 330:615-622.

Liu Y, Peter D, Roghani A, Schuldiner S, Prive GG, Eisenberg D, Brecha N, Edwards RH (1992) A cDNA that suppresses $\mathrm{MPP}^{+}$toxicity encodes a vesicular amine transporter. Cell 70:539-551.

MacMillan-Crow LA, Crow JP, Kerby JD, Beckman JS, Thompson JA (1996) Nitration and inactivation of manganese superoxide dismutase in chronic rejection of human renal allografts. Proc Natl Acad Sci USA 93:11853-11858.

Marletta MA (1994) Nitric oxide synthase: aspects concerning structure and catalysis. Cell 78:927-930.

Matsui T, Ohta A, Takagi H (1996) Morphological studies on Mn-SOD, NOS and calcium binding proteins in the rat hippocampus. Osaka City Med J 42:1-13.

McCord JM (1969) Superoxide dismutase: an enzymatic function for erythrocuprein (hemocuprein). J Biol Chem 244:6049-6055.

Meldrum B, Garthwaite J (1990) Excitatory amino acid neurotoxicity and neurodegenerative disease. Trends Pharmacol 11:379-387.

Nathan C, Xie QW (1994) Nitric oxide synthases: roles, tolls, and controls. Cell 78:915-918.

Nathan CF (1992) Nitric oxide as a secretory product of mammalian cells. FASEB J 6:3051-3064.

Oberley LW, Spitz DR (1985) Nitroblue tetrazolium. In: CRC handbook of methods for oxygen radical research (Greenwald R, ed), pp. 217-220. Boca Raton, FL: CRC.

Oberley TD, Oberley LW, Slattery AF, Lauchner LJ, Elwell JH (1990) Immunohistochemical localization of antioxidant enzymes in adult Syrian hamster tissues and during kidney development. Am J Pathol 137:199-214.

Przedborski S, Jackon-Lewis V, Yokohama R, Shibata T, Dawson VL, Dawson TM (1996) Role of neuronal nitric oxide in 1-methyl-4phenyl-1,2,3,6-tetrahydropyridine (MPTP)-induced dopaminergic neurotoxicity. Proc Natl Acad Sci USA 93:4565-4571.

Radi R, Beckman JS, Bush KM, Freeman BA (1991) Peroxynitrite oxidation of sulfhydryls. The cytotoxic potential of superoxide and nitric oxide. J Biol Chem 266:4244-4250.

Roskams AJ, Bredt DS, Dawson TM, Ronnett GV (1991) Nitric oxide mediates the formation of synaptic connections in developing and regenerating olfactory receptor neurons. Neuron 13:289-299.

Rothstein JD, Dykes-Hoberg M, Pardo CA, Bristol LA, Welty DF (1996) Knockout of glutamate transporter reveals a major role for astroglial transport in excitotoxicity and clearance of glutamate. Neuron 16:675-686.

Samdani A, TM Dawson TM, Dawson VL (1997) Nitric oxide synthase in models of focal ischemia. Stroke 28:1283-1288.

Schinder AF, Olson EC, Spitzer NC, Montal M (1996) Mitochondrial dysfuction is a primary event in glutamate neurotoxicity. J Neurosci 16:6125-6133.

Schmidt HHHW, Walter U (1994) NO at work. Cell 78:919-925.

Schulz JB, Matthews RT, Jenkins BG, Ferrante RJ, Siwek D, Henshaw DR, Cipolloni PB, Mecocci P, Kowall NW, Rosen BR, Beal MF (1995a) Blockade of neuronal nitric oxide synthase protects against excitotoxicity in vivo. J Neurosci 15:8419-8429.

Schulz JB, Matthews RT, Muqit MMK, Browne SE, Beal MF (1995b) Inhibition of neuronal nitric oxide synthase by 7 -nitroindazole protects against MPTP-induced neurotoxicity in mice. J Neurochem 64:936-939.

Schulz JB, Huang PL, Matthews RT, Passov D, Fishman MC, Beal MF (1996) Striatal malonate lesions are attenuated in neuronal nitric oxide synthase knockout mice. J Neurochem 67:430-433.

Schweizer M, Richter C (1994) Nitric oxide potently and reversibly deenergizes mitochondria at low oxygen tension. Biochem Biophys Res Commun 204:169-175.

Spitz DR, Oberley LW (1989) An assay for superoxide dismutase activity in mammalian tissue homogenates. Anal Biochem 179:8-18.

Standaert DG, Landwehrmeyer GB, Kerner JA, Penney JB, Young AB (1996) Expression of NMDAR2D glutamate receptor subunit mRNA in neurochemically identified interneurons in the rat neostriatum, neocortex, and hippocampus. Mol Brain Res 42:89-102.

Thomas E, Pearse AGE (1964) The solitary active cells. Histochemical demonstration of damage-resistant nerve cells with a TPN-diaphorase reaction. Acta Neuropathol (Berl) 3:238-249. 
Troy CM, Derossi D, Prochiantz A, Greene LA, Shelanski ML (1996) Downregulation of $\mathrm{Cu} / \mathrm{Zn}$ superoxide dismutase leads to cell death via the nitric oxide-peroxynitrite pathway. J Neurosci 16:253-261.

Uemura Y, Kowall NW, Beal MF (1990) Selective sparing of NADPHdiaphorase-somatostatin-neuropeptide $\mathrm{Y}$ neurons in ischemic gerbil striatum. Ann Neurol 27:620-5.

Velculescu VE, Zhang L, Vogelstein B, Kinzler KW (1995) Serial analysis of gene expression. Science 270:484-487.

Vincent SR, Kimura H (1992) Histochemical mapping of nitric oxide synthase in the rat brain. Neuroscience 46:755-784.

Werner M, Madreperla S, Lieberman P, Adler R (1990) Expression of transfected genes by differentiated, post-mitotic neurons and photoreceptors in primary cell cultures. J Neurosci Res 25:50-57.

White, RJ, Reynolds IJ (1996) Mitochondrial depolarization in glutamate-stimulated neurons: an early signal specific to excitotoxin exposure. J Neurosci 16:5688-5697.

Wong GHW (1995) Protective roles of cytokines against radiation: induction of mitochondrial MnSOD. Biochem Biophys Acta 1271:205-209.

Wong GHW, Elwell JH, Oberley LW, Goeddel DV (1989) Manganous superoxide dismutase is essential for cellular resistance to cytotoxicity of tumor necrosis factor. Cell 58:923-931.

Xia Y, Dawson VL, Dawson TM, Snyder SH, Zweier JL (1996) Nitric oxide generates superoxide and nitric oxide in arginine-depleted cells leading to peroxynitrite-mediated cellular injury. Proc Natl Acad Sci USA 93:6770-6774.

Yun H-Y, Dawson VL, Dawson TM (1996) Neurobiology of nitric oxide. Crit Rev Neurobiol 10:291-316.

Zhang J, Dawson VL, Dawson TM, Snyder SH (1994) Nitric oxide activation of poly(ADP-ribose) synthetase in neurotoxicity. Science 263:687-689.

Zhang Y, Marcillat O, Giulivi C, Ernster L, Davies KJ (1990) The oxidative inactivation of mitochondrial electron transport chain components and ATPase. J Biol Chem 265:16330-16336. 